\title{
Numerical modelling of physical processes governing larval transport in the southern North Sea
}

\author{
M. C. H. Tiessen ${ }^{1}$, L. Fernard ${ }^{2}$, T. Gerkema ${ }^{1}$, J. van der Molen ${ }^{2}$, P. Ruardij ${ }^{1}$, and H. W. van der Veer ${ }^{1}$ \\ ${ }^{1}$ Royal Netherlands Institute for Sea Research, P.O. Box 59, 1790 AB Den Burg, Texel, the Netherlands \\ ${ }^{2}$ Centre for Environment, Fisheries and Aquaculture Science (CEFAS), Pakefield Road, Lowestoft, Suffolk NR33 0HT, UK \\ Correspondence to: M. C. H. Tiessen (meinard.tiessen@ nioz.nl)
}

Received: 29 August 2013 - Published in Ocean Sci. Discuss.: 17 October 2013

Revised: 28 February 2014 - Accepted: 9 March 2014 - Published: 21 May 2014

\begin{abstract}
A three-dimensional hydrodynamic model (GETM) was coupled with a particle tracking routine (GITM) to study the inter-annual variability in transport paths of particles in the North Sea and English Channel. For validation, a comparison with observed drifter trajectories is also presented here. This research investigated to what extent variability in the hydrodynamic conditions alone (reflecting passive particle transport) contributed to interannual variability in the transport of eggs and larvae. In this idealised study, no a priori selection of specific spawning grounds or periods was made and no active behaviour (vertical migration) or mortality was included. In this study, egg and larval development towards coastal nursery areas was based solely on sea water temperature, while settlement areas were defined by a threshold water depth. Results showed strong inter-annual variability in drift direction and distance, caused by a combination of wind speed and direction. Strong inter-annual variability was observed both in absolute amount of settlement in several coastal areas, and in the relative importance of the different areas. The effects of wind and temperature variability are minor for settlement along the western shores of the North Sea and in the English Channel, but have a very significant impact on settlement along the eastern shores of the North Sea. Years with strong south-westerly winds across the Dover Straight resulted in higher settlement figures along its eastern shores of the North Sea (standard deviation $37 \%$ of the mean annual settlement value). Settlement in the western Dutch Wadden Sea did not only show inter-annual variability, but patterns were also variable within each year and revealed seasonal changes in the origin of particles: during winter, stronger currents along with colder temperatures generally result in particles originating from further away.
\end{abstract}

\section{Introduction}

The pelagic phase is a characteristic component of the life cycle of the majority of marine species. Within the range from holoplankton to holobenthos species a variety of different life strategies occur, including benthic resting stages in plankton species (such as, among others, dinoflagellates (Dale, 1985) and cnidaria (Boero et al., 1991)) and pelagic egg and larval stages in benthic bivalves and demersal fish species. Marine species can only exist in geographic locations within which there can be continuity in the life cycle; i.e. "in a geographical setting within which retention (membership) of the population exceeds losses (vagrancy) in some integrated sense for the life cycle as a whole" (cf. Sinclair, 1988). The importance of life cycle closure is continuously topical since at any stage of the life cycle an individual can become separated from its population either by spatial (losses from distributional areas) or by energetic (predation, starvation, disease) processes. The variety of all these complex life stages can be viewed as species-specific and/or local adaptations to ultimately achieve life cycle closure.

During the pelagic phase physical factors such as advection and temperature are acting on and potentially resulting in the dispersal of individuals, depending on strength and duration of the physical forcing. Especially for species with a pelagic egg and larval stage, this period of egg and larval drift is considered to be an important factor in yearclass strength regulation (bivalves: Thorson, 1966; fishes: Leggett and Deblois, 1994; flatfishes: Van der Veer, 1986; Van der Veer et al., 2000; Van der Veer and Leggett, 2005). As a consequence, the impact of inter-annual variability in hydrodynamic conditions on egg and larval transport has been studied since large-scale two-dimensional and later 
three-dimensional hydrodynamic transport models have become available. For the North Sea area this has resulted in a number of detailed studies on egg and larval drift and transport of fish larvae, especially flatfishes (Van der Veer et al., 1998; de Graaf et al., 2004; Bolle et al., 2009; Dickey-Collas et al., 2009; Savina et al., 2010; Hufnagl et al., 2013; Lacroix et al., 2013) and all these studies stress the importance of drift and transport during the pelagic phase.

Passive transport is the only agent during egg development but from hatching onwards also larval behaviour such as active vertical migration may come into play (Rijnsdorp et al., 1985). In the recent three-dimensional hydrodynamic modelling studies by van der Molen et al. (2007), Dickey-Collas et al. (2009), Bolle et al. (2009), Savina et al. (2010), Hufnagl et al. (2013), and Lacroix et al. (2013) both passive transport and active behaviour components were included thereby preventing an analysis of their relative importance. In particular, it remains unclear to what extent physical factors alone can be responsible for inter-annual variability.

The aim of the present paper was to determine the importance of passive transport by advection and the impact of physical factors alone on the dispersal of particles in the southern North Sea (Fig. 1), whereby we used plaice Pleuronectes platessa as model species. By way of validation, we start with a comparison of simulated model trajectories with observed drifter paths. Particle tracking was introduced by means of a three-dimensional Lagrangian tracer model in combination with a hydrodynamic model. Instead of selecting specific release areas (reflecting spawning grounds) and time periods (reflecting spawning periods), as was done by de Graaf et al. (2004) and Bolle et al. (2009), no a priori selection was made; the entire southern side of the North Sea and the English Channel were selected as potential starting points (cf. Hufnagl et al., 2013) for particles over a 4-month period in winter and spring, reflecting the most important period for egg and larval drift in plaice larvae (Talbot, 1977; Harding et al., 1978). Particles were released at random over latitude, longitude, depth and time. With regards to the transport of larvae (such as of plaice Pleuronectes platessa), we used sea water temperature to define a pelagic life span (Bolle et al., 2009). When development into a juvenile was completed, settling was assumed to take place at the first opportunity when a particle would encounter an area with a certain minimum threshold depth. In this way, the success of settling could be defined and mapped.

\section{Material and methods}

\subsection{Hydrodynamic model}

The hydrodynamic model used in this research is the threedimensional General Estuarine Transport Model (GETM). GETM incorporates the General Ocean Turbulence Model (GOTM), which is a one-dimensional model over the vertical

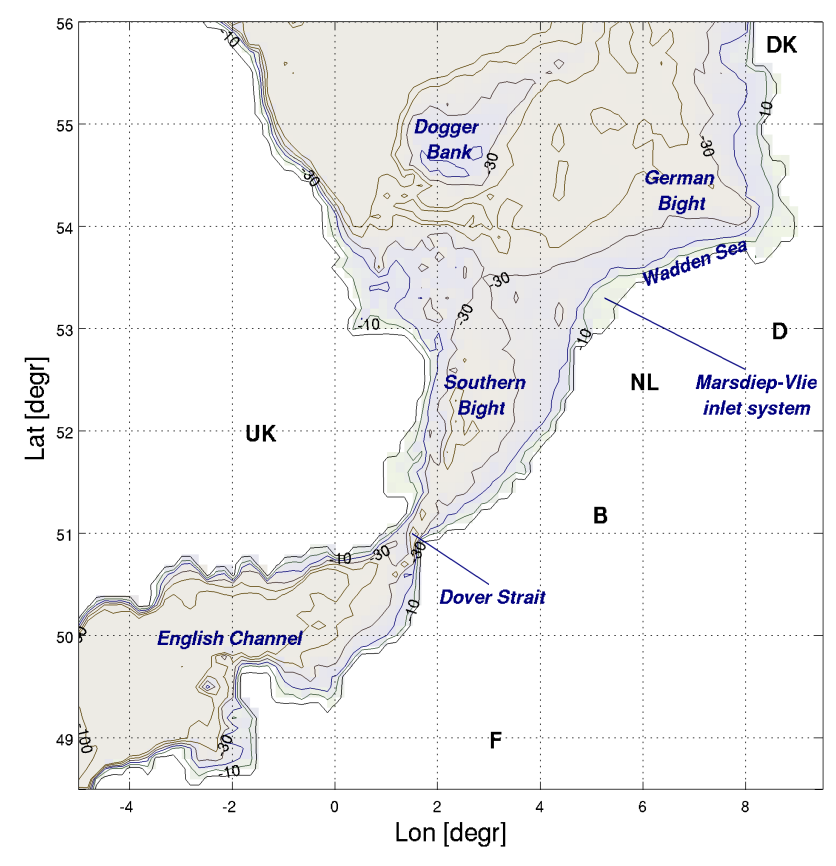

Figure 1. Topography of the research area, along with area and location names. Note that the area shown does not correspond with the entire domain of the hydrodynamic simulations, which spans $48.2-60.1^{\circ} \mathrm{N},-7-16.9^{\circ} \mathrm{E}$, and includes part of the Baltic sea.

that provides a variety of turbulence closure schemes. The combined 3-D hydrodynamic model suite was developed by Burchard and Bolding (2002). It has been applied to coastal seas such as the North Sea and Baltic Sea (Ruardij et al., 2005; Lenhart et al., 2010; Gräwe and Burchard, 2011; Van Leeuwen et al., 2012; Aldridge et al., 2012). The model can implement the inflow of fresh water and describes the development of stratification in the domain, both as a result of salinity and temperature gradients. The vertical tides and meteo-forcing are prescribed at the open boundaries.

In the present study, the model runs were based on GETMERSEM (European Regional Seas Ecosystem Model; Van Leeuwen et al., 2012; Ruardij et al., 2005) and were set up to describe the North Sea and part of the Baltic (48.2$\left.60.1^{\circ} \mathrm{N},-7-16.9^{\circ} \mathrm{E}\right)$. The model grid was 6 nautical miles (approximately $10 \mathrm{~km}$ ) in the horizontal, and 26 sigma-layers were used over the vertical. Open model boundaries were located at the English Channel and between the North Sea and North Atlantic. At these boundaries the surface elevation and currents were forced by data from a barotropic shelf-wide model, which in turn was forced with the Topex Poseidon altimetry data (Topex Poseidon, http://podaac.jpl.nasa.gov/). Monthly sea water temperature and salinity values according to (Janssen et al., 1999) were introduced at each grid-point as initial conditions. Both the volume and salinity effects of the various rivers flowing into the North Sea were provided by local agencies (see Acknowledgements). The ECMWFreanalysis provided the meteorological forcing (ECMWF, 
http://www.ecmwf.int/). The hydrodynamic model was run for the entire duration between 1993 and 2005. From December to July of each year, the hydrodynamic conditions were stored at 45 min intervals to provide a high enough temporal resolution to describe currents during the M2 tidal cycle, which is the main tidal component in the central and southern North Sea.

\subsection{Particle tracking model}

The three dimensional Lagrangian tracer model (GITM) used in combination with the GETM hydrodynamic model was originally developed by Wolk (2003). A re-programmed version has recently been expanded upon, by Van der Molen (unpublished data), with modules to allow for egg and larval development and vertical migration behaviour in similarity to the work presented in Van der Molen et al. (2007). The model describes the motion of a number of discrete particles through a 3-D velocity field. This velocity field is provided by the hydrodynamic model. The particle tracking model divides the motion into an advective and a diffusive component. The advection equation is solved analytically. Turbulence is accounted for by the random walk model (Hunter et al., 1993) where the vertical diffusivity is calculated by the turbulence model in GETM using the Kolmogorov-Prandtl relation (Burchard and Bolding, 2002). Horizontal diffusion is here excluded from the particle drift, and the displacement of particles is therefore governed by the output of current velocities from the model. The internal time step of $10 \mathrm{~s}$ is chosen to ensure accuracy of the tracer model.

\subsection{Set-up of plaice model runs}

Instead of selecting specific spawning grounds and periods (as was done by: Van der Veer et al., 1998; de Graaf et al., 2004; Van der Molen et al., 2007; Bolle et al., 2009), here no a priori selection has been made. This allows for more flexibility in the interpretation. The entire southern side of the North Sea and the English Channel were selected as starting points for particles. Particles were released at random over latitude, longitude, depth and time. A total of 1000000 particles were released between $48.5-56^{\circ} \mathrm{N}$ and $-5-9.5^{\circ} \mathrm{E}$, between 1 December (of the preceding year) and 31 March (Fig. 2). For instance, for the Southern Bight of the North Sea, this translates in approximately 5800 particles being released every week. Development rates of particles (simulating plaice larvae) were derived from Bolle et al. (2009), but no biological behaviour or active vertical migration was included in the later stages of the particle evolution. After the final larval stage, a settlement stage, lasting up to 30 days, followed. During this stage, a particle would settle if it encountered favourable conditions. The only prerequisite for a suitable settlement location was a predefined threshold water depth: when particles would flow through a grid-cell whose minimum depth (at one of the corners) was less than $10 \mathrm{~m}$,

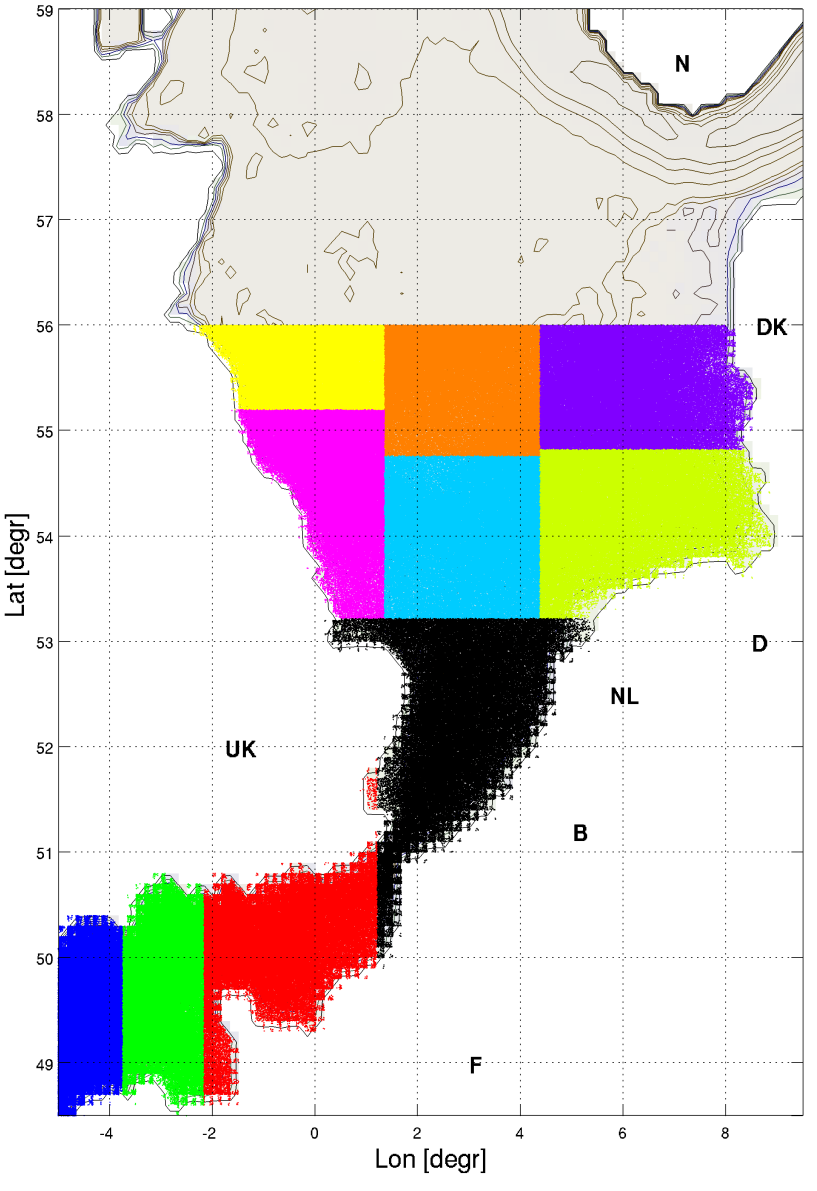

Figure 2. Release distribution of particles for the numerical runs. Colour of the dots solely indicates the release position.

then it was assumed this particle would settle. The duration of the pelagic life span of particles depended on the water temperature, as this determined the duration of the different life stages (as was the case in Bolle et al., 2009). The water temperature experienced by each particle was determined over time by interpolation of the 3-D temperature fields provided by the hydrodynamic model. A maximum pelagic life span (which included the settlement stage) of 120 days was imposed, at which point model runs were truncated. No mortality was incorporated.

\subsection{Validation of the drift model}

Validation of the model was done by a comparison with a number of trajectories made by drifter buoys. During the spring and summer of 2000, CEFAS (Centre for Environment, Fisheries and Aquaculture Science; UK) released over 30 drifters in the central and southern North Sea. These drifters were equipped with a drogue floating at a preprescribed depth, which was attached to a floating buoy providing the communication with a satellite. The drogue consisted of a large cylindrical shape with a diameter of $1.5 \mathrm{~m}$ 
and a length of approximately $7 \mathrm{~m}$. The drogue was kept at a depth of $10 \mathrm{~m}$. Drifter paths lasted up to 60 days, but were all eventually truncated. This was generally due to fishing activities accidentally cutting the wire between the drogue and the surface buoy. The subsequent drift of the surface buoy was (although recorded) not included in the comparison here, as the ensuing (rapid) drift was driven by surface waves and direct wind effects, which were not included in the numerical simulations.

The present validation comparison focussed on six drifters released in the Southern Bight, since this formed the target area for plaice larvae drift. Additionally, only drift durations of more than 20 days were included. Certain drifter buoys were also excluded as they drifted shoreward into areas with a water depth of less than $15 \mathrm{~m}$, which would mean that the drogue might be touching the bed, affecting the drift direction and speed.

The drift trajectories were reproduced by releasing particles in the numerical model at the same time and location and at a depth of $10 \mathrm{~m}$. This depth was chosen to cover both the drag effect of the drogue and the minor contribution of the surface buoy (Niiler et al., 1995). For these runs vertical diffusion was excluded to ensure that the modelled particles remained at the same depth as the drifter buoys.

\section{Results}

\subsection{Validation}

A comparison between the drift of the buoys and their modelled counterparts shows that the model reproduces the general trend of the drifters reasonably well (Fig. 3). At the end of the drift, buoy positions and modelled particle locations have diverged, as can be seen by the distance between the final dot for each colour and the end of the colourcorresponding line. However, there is no general trend in this divergence, suggesting that the model does not over- or under-predict the overall residual current patterns. The error that developed over time between each of the drifter buoys and the modelled particles was less than $10 \%$ of the total drifted distance of each of the buoys, indicating a fairly good agreement between predicted and observed drift paths. To put the discrepancy between modelled and actual trajectories into perspective, this divergence was compared to the modelled spread of particles released in the proximity of the drifter release point (Fig. 4) Along with the single modelled particle being released at the same position and time as each of the drifter buoys, additional modelled particles were positioned in a $10 \mathrm{~km}$-wide circle around the drifter release-point. The initial distance between the central particle and the particles in the circle was chosen to roughly correspond to the tidal excursion as was displayed by the drifter buoys. With time, the circle gets deformed, and the distance between particles in the circle and the central particle increases (Fig. 4).

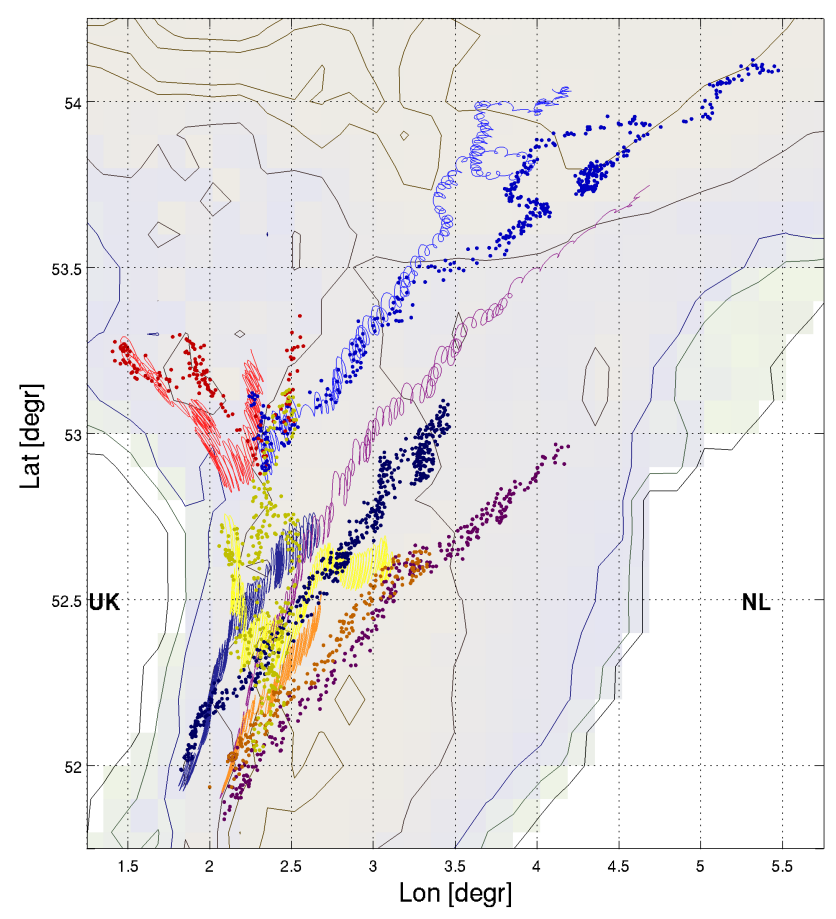

Figure 3. Comparison between six drifter paths (different coloured dots) and modelled trajectories (shown in differently coloured lines). The starting-point of each of the drifter-buoy pairs is shown as a thicker circle, and is generally located close to the UK coast.

Significant differences between the different drifter buoys and their modelled equivalents exist. For the buoys that cover the longest distance (blue and purple, see Fig. 3), the particles in the circle show the smallest deformation to develop over time, with the circle of particles remaining close to 0 . However, the buoys that show a more complicated drift pattern (in particular red, yellow and dark blue) show a much bigger spread of the circle of particles to develop over time. Overall, however, the accuracy of the model predictions is fairly reasonable, in the sense that the maximum spread of the particles originally released in a circle is of the same size as the difference between the drifter buoys and the corresponding modelled central particle.

\subsection{Particle drift and settlement success}

In the following sections, an in-depth investigation into the hydrodynamic causes of inter-annual variability in larval transport and settlement success is presented. The analysis will first be applied to the numerical runs of plaice eggs and larvae for a single year (2001), followed by a comparison between the different years. The year 2001 was chosen as this year seems to be a very moderate year, not only considering hydrodynamic conditions (for a comparison with SST (sea surface temperature) values for other years, see Van der Veer and Witte (1999), but also with respect to settlement success 

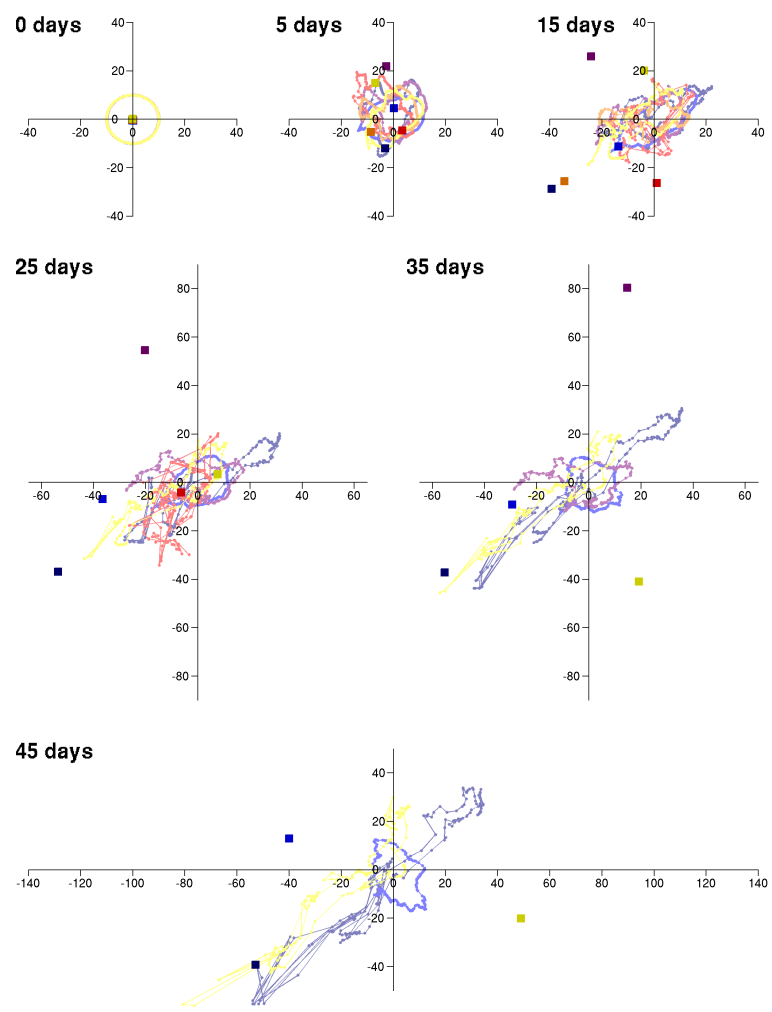

Figure 4. At different moments during the drifter-buoy track, the difference between the drifter path and the corresponding modelled trajectory is shown (as squares, with the different tracks shown in different colours) with, on top of that, the current position of particles released in a circle around the drifter position. The $x$ and $y$ axis represent kilometres of spread. With time, the distance between the actual drifter position and that of the modelled particles increases (as can also be seen in Fig. 3). The spread of particles originally released in a circle around the central particle deforms and expands over time.

rates, as shown in data of the Balgzand area (Van der Veer et al., 2009).

In Fig. 5, the final position of particles is shown at the end of their pelagic life span (up to 120 days). Please note that in order to facilitate the interpretation of the figure, only a small section of the total number of particles released is shown in this figure. Only particles released from 25 December to 6 January (100 000 particles) are shown. Particles that "settled" (i.e. reached an area shallower than the threshold depth of $10 \mathrm{~m}$ in their final pelagic stage) are not included in this figure as their drift was truncated prematurely. The particles showed a significant displacement over this period of time. Especially particles released in the Southern Bight (black) and the English Channel (red) showed drift over a large distance. The particles drifted in an anticlockwise fashion, especially in the central North Sea. This conformed with the typical circulation pattern (Otto et al., 1990; Sündermann and Pohlmann, 2011). Just south-west of Dover Straight and along the eastern shores, particles showed the largest drift

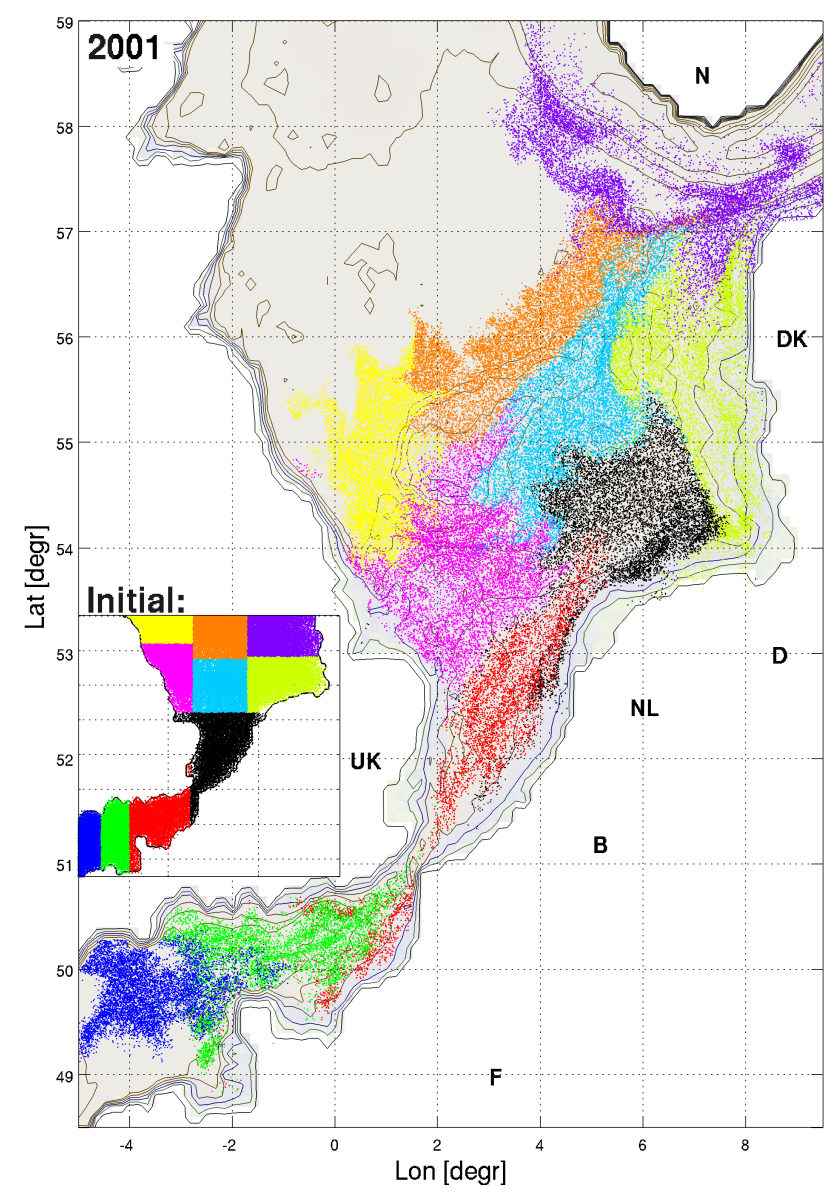

Figure 5. Distribution of particles at the end of their pelagic life span (up to 120 days). Only shown are particles that do not settle and to improve clarity only 100000 particles that were released around 1 January are included. The colour of the dots corresponds to the release location of the particles, which is shown in the inset.

distance (towards NE), whereas drift distances around Dogger Bank were smallest.

Settlement success (of all of the 1000000 particles released) was not only dependent on the particle drift direction, but also on the particle development (Fig. 6). Particles mainly settled along the coastlines of the North Sea, but also in the central parts of the Southern Bight and the English Channel. Additionally, pie charts show the percentages of different outcomes of the numerical simulations: prolonged development inhibiting particles to reach settlement stage (red) only occurred in the German Bight. This red segment of the pie charts corresponds to particles that are still in their larval stage when simulations are truncated after 120 days. However, also large parts of the central North Sea (for at least a period of time) contained particles with reduced development rates, as these only reached the beginning of the settlement stage (orange). The orange segment represents particles that had spent fewer than 30 days in their settlement stage, before the simulation was truncated after 120 days. As a result, 


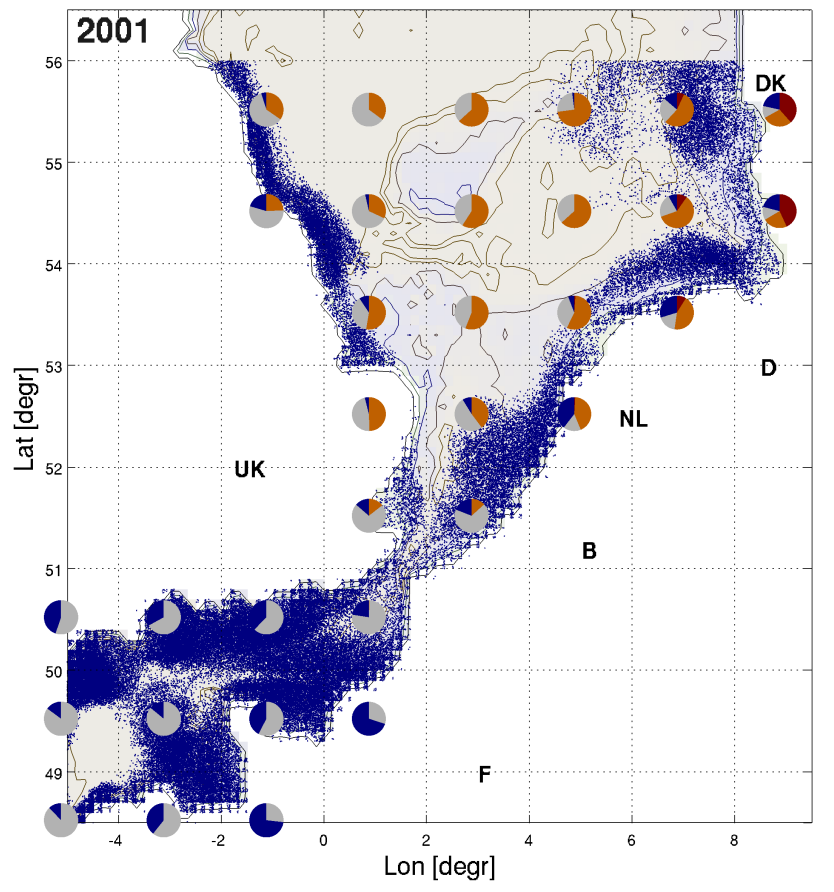

Figure 6. Distribution of the origin of particles that settle (shown in blue dots). Please note that all 1000000 particles are included in this figure. On top of that, different pie charts show the geographic variation of the different outcomes of particle development and drift: (blue) particles that settle; (grey) particles that do not settle; (orange) particles that do not settle but also do not reach end of the 3-day settlement stage before the numerical simulation is truncated after 120 days; (red) particles that do not settle as these have not yet reached the beginning of their 30-day settlement stage, before simulation is truncated. The red segment of the pie charts indicates particles that are still in their larval stage after 120 days.

these particles had only a reduced period during which a particle could drift into a suitable settlement location. The geographic variation in the success rate of a particle reaching the settlement stage closely corresponded to the water temperature (van der Veer and Witte, 1999). The lowest temperatures occurred in the German Bight and along the Danish Coast, the same area where particles did not reach the settling stage due to their prolonged development. The highest water temperatures occurred in the English Channel, where all released particles reached the end of the settling stage before the 120day model-run duration ended. Note, however, that the particle development took place during the entire particle drift, and that therefore particles may have passed through a range of water temperatures in space and time.

The geographic origin of particles that settled in the different coastal zones can be seen in Fig. 7. The coastlines around the southern North Sea and the English Channel are divided into different zones. Particles settling in the western part of the Wadden Sea (the red part) largely originated from the Southern Bight. A clear divide can be seen between the

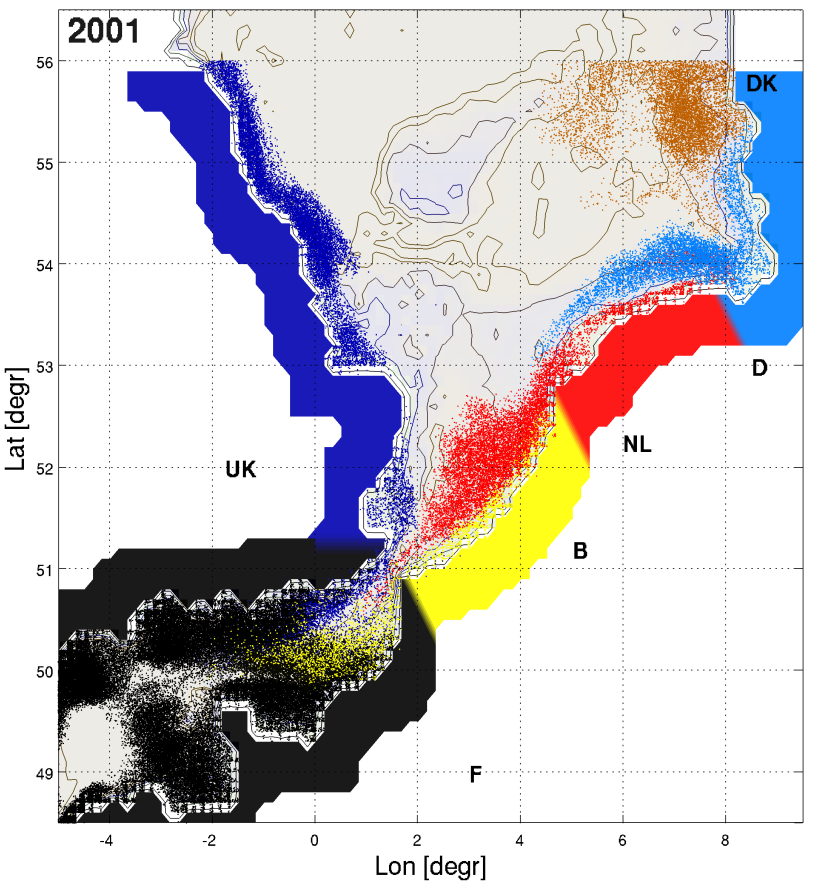

Figure 7. Release location of particles, with the settlement location shown in the colour of the dots. Additionally, the different settlement areas are indicated with a colour-corresponding band along the coastline. (dark blue) Settlement in the North Sea coastal zone of the UK; (black) settlement along the coast of the English Channel (both France and UK); (yellow) settlement in the French, Belgian and Dutch North Sea coast; (red) settlement in the western part of the Wadden Sea; (light blue) settlement in the northern part of the Wadden Sea; (orange) settlement outside of the shown domain (generally along the northern Danish and Norwegian coast). Please note that the coarse model grid does not include any Wadden Sea islands, and therefore there is no distinction between settlement on the North Sea side of these islands, and in the Wadden Sea itself.

origin of particles settling in the western Wadden Sea and the north-eastern Wadden Sea (light blue). Particles released in the Dutch coastal zone generally settled in the western Wadden Sea, whereas particles released only slightly further offshore, drifted into the German Bight before settling. This principle also applied to the other continental coastal areas.

\subsection{Inter-annual variability}

Numerical runs were carried out for the years 1994-2005. Some characteristic values for all the different years will be compared but, initially, a comparison between two extreme years (1996 and 1998) and the "moderate" year (2001) presented previously will be discussed.

The overall displacement of the section of particles released around 1 January of 1996 and 1998 show significant differences (Fig. 8). The particle drift direction of 1998 was roughly the same as that presented for 2001, mainly towards the north-east along the eastern shores of the North Sea and 

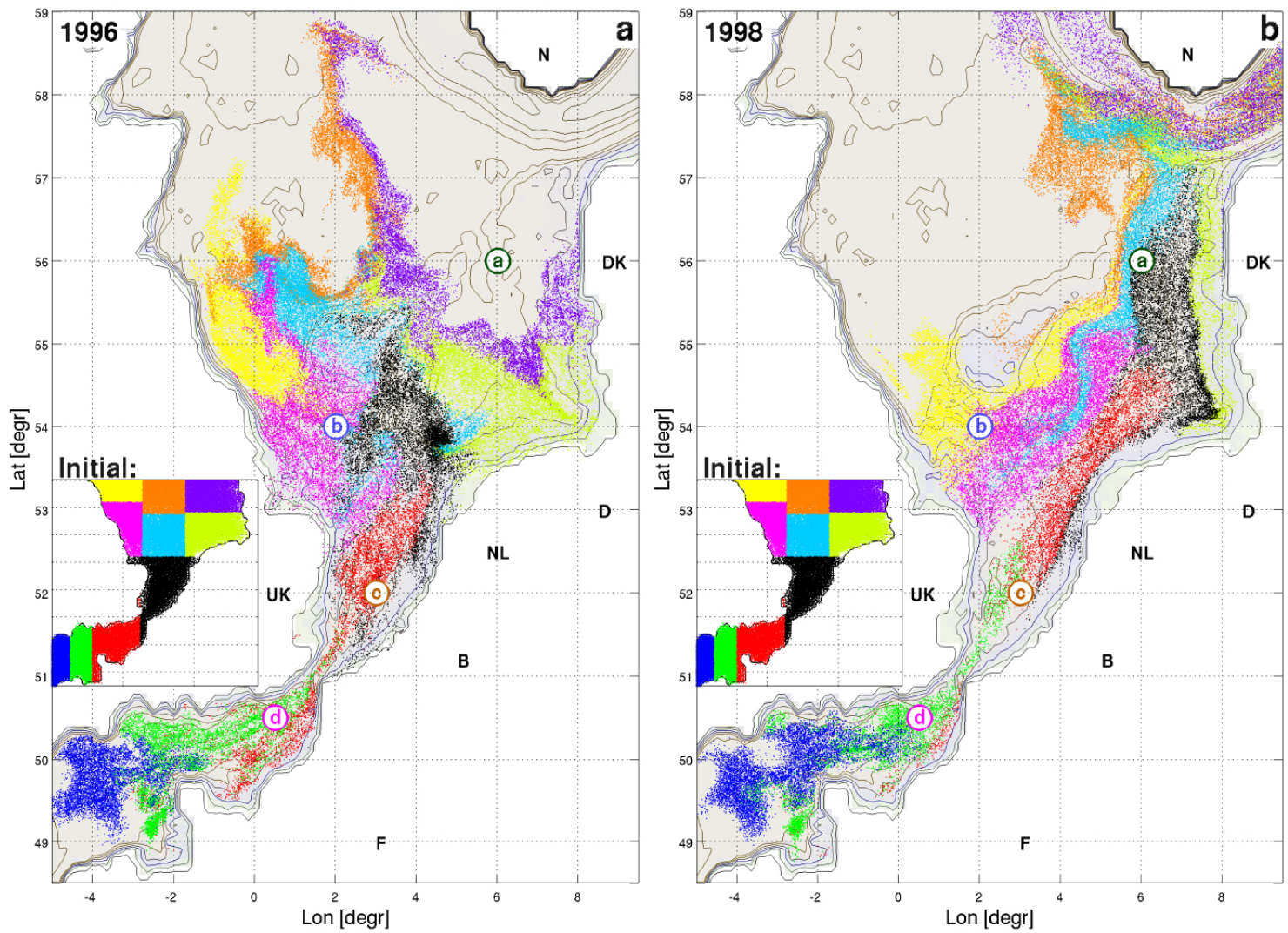

Figure 8. Distribution of particles at the end of their pelagic life span (up to 120 days) (a) 1996; (b) 1998. Only shown are particles that do not settle. Only 100000 particles that were released around 1 January are included. The colour of the dots corresponds to the release location of the particles, shown at the inset. Locations "a" to "d" correspond to data shown in Figs. 9 and 14.

Table 1. Relationship between variability in forcing conditions and changes in settlement success. Settlement success is represented be the variability in the number of settling particles and by the number of particles with truncated development. The forcing conditions constitute the SST over February for each year at station d, and the percentages of wind intensity from the south-west at station d (the intensity is determined as the average wind speed from this direction times the percentage of time the wind is coming from this direction, this value is then divided over sum of intensities for all wind directions). CV stands for coefficient of variation (SD/mean $\times 100)$, SD for standard deviation, and Corr. for Correlation coefficient. Bold numbers indicate a high correlation.

\begin{tabular}{lrrrrr}
\hline & Mean & SD & CV (\%) & Corr. Temp & Corr. Wind \\
\hline Total number of settling particles & 119412 & 9827 & 8 & 0.61 & 0.50 \\
Total number of particles with truncated development & 235441 & 147904 & 63 & $\mathbf{- 0 . 7 7}$ & $\mathbf{- 0 . 7 2}$ \\
\hline
\end{tabular}

in the English Channel. In 1996, no clear overall drift direction could be observed. There was only a very small portion that showed a similar trend to that of 1998 and 2001, located around the Dover Strait. Particles released in the central North Sea seemed to drift towards the west and north-west, instead of towards the north-east (as occurred for 1998 and 2001). Drift distance was also very different for both years, with 1998 showing bigger drift distances than 2001, while these were significantly reduced for 1996 . Both the changes in drift direction and distance were the result of significantly different wind patterns for 1996 in comparison with 1998 (with 2001 being similar to 1998) (Fig. 9). In 1998 and 2001 the prevailing wind direction and the highest average wind speeds were south-westerly for stations c and d. For 1996, the exact opposite wind forcing can be observed.

The different drift directions in 1996 resulted in very different settlement success levels (of the 1000000 particles released) (Fig. 10). A very large portion of particles across the southern and eastern parts of the North Sea did not reach the settlement stage within 120 days (shown in the red segments of the pie-charts), and particles did not reach the end of the settling stage (shown in orange) in the entire North Sea. Much smaller numbers of particles released from the Southern and German bights settled compared to both 2001 and 


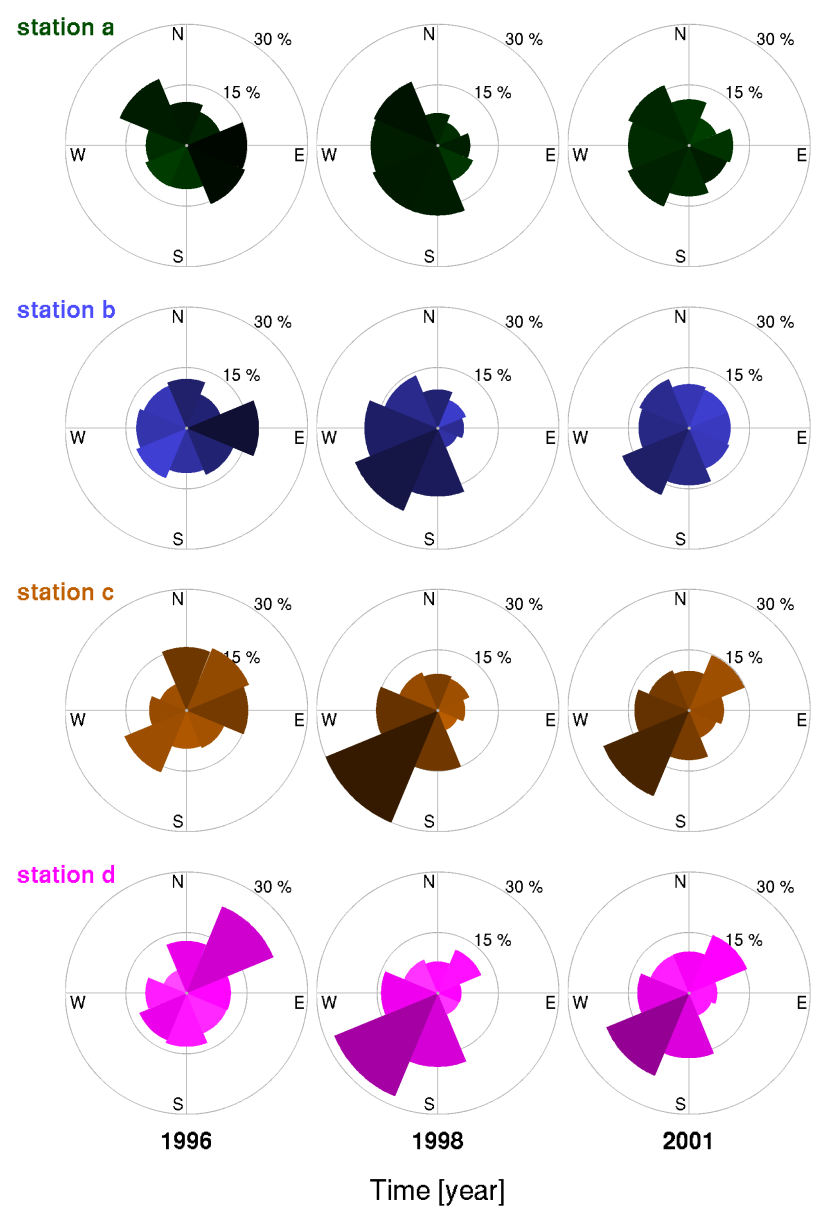

Figure 9. Wind speed and direction at the different stations (see Fig. 8) for 1996 (left), 1998 (middle) and 2001 (right) over the 8 months over which the particle drift was computed, starting with December of the previous year, while finishing in July. The size of the pie-pieces is defined by the percentage of time that the wind is coming from this direction. The colour of the pieces indicates the average wind speed.

1998. Not only were the currents in 1996 very different from 2001 and 1998, also the water temperature was much lower. The inflow of warm English Channel water was significantly reduced while the cold water patch in the German Bight and along the Danish coast was chilled and expanded across the central North Sea, resulting in the slow development experienced by particles released in these areas. The SST distribution in 1998 was similar to that of 2001, with only a slightly increased SST across the model domain. The result was that almost all (except in the most easterly parts of the German Bight) particles reached both the start and end of the settlement stage. In comparison with 2001, 1998 showed a very similar distribution of successful settlement of particles.

The inter-annual variability in currents and water temperature caused not only changes in settlement success but also in location of settlement (Fig. 11). Along the eastern coast of the UK and in the English Channel, the settlement locations of particles were similar for 1996, 1998 and 2001. However, the origin of particles settling in for instance the western part of the Wadden Sea (red) changed significantly over the years. In 1998, particles released from the Dover Strait reached this settlement area (similar to 2001), whereas in 1996 the origin of particles settling here was restricted to the settlement area itself and along the Dutch North Sea coast. Additionally, the stronger currents experienced in 1998 (compared to 2001), increased the number of particles settling along the northern shores of Denmark and along Norway: in 2001, a collection of particles released just north of the Dutch Wadden Isles would settle in the German Bight and along the Danish Wadden Sea coast; in 1998 such a plume could not be seen and particles released only slightly further offshore now reached the Norwegian Trench (shown in orange).

The final status of each particle was grouped in different outcomes for each year separately in Fig. 12. The total number of settling particles (shown in blue) showed only limited variability, with a coefficient of variability $(\mathrm{CV})$ of only $8 \%$, while the number of particles with truncated development (depicted in orange and red) showed a strong variability over the years $(\mathrm{CV}=63 \%)$, which can be linked to hydrodynamic conditions. Table 1 shows the correlation coefficients between the final status of a particle (more specifically: settlement or truncated development) and two characteristic forcing conditions. The inter-annual variability in the monthly average sea surface temperature for February (as shown in Fig. 10c, d) at station d, shows a good correlation with the number of particles with truncated development, as increased water temperatures reduce development times. Additionally, in years with a higher percentage of south-westerly prevailing winds (at station d), there was a drift of warm English Channel water into the Southern Bight, increasing the water temperatures experienced by the majority of particles, resulting in a high correlation between this wind characteristic and development success. Additionally, with the small variability in the total number of settling particles, the correlation between this variability and the forcing conditions is smaller (temperature: 0.61; wind: 0.50).

Closer inspection of the number of particles that settled in the different zones (as shown in Fig. 7), showed that the largest number of settling particles did so in the English Channel (Fig. 13). As the particles were released at random over space (including depth), a significantly large portion of particles was released in the (relatively deep) English Channel. The inter-annual trends in settling numbers for each zone illustrated that the number of settling particles along the North Sea coast of the UK (dark blue) and the English Channel (black) was reasonably constant (CV is 8 and $6 \%$, respectively, see Table 2), with the majority of the variability originating from the particles settling along the eastern shores of the North Sea (yellow, red, light blue and orange). These settlement zone characteristics roughly coincided with 

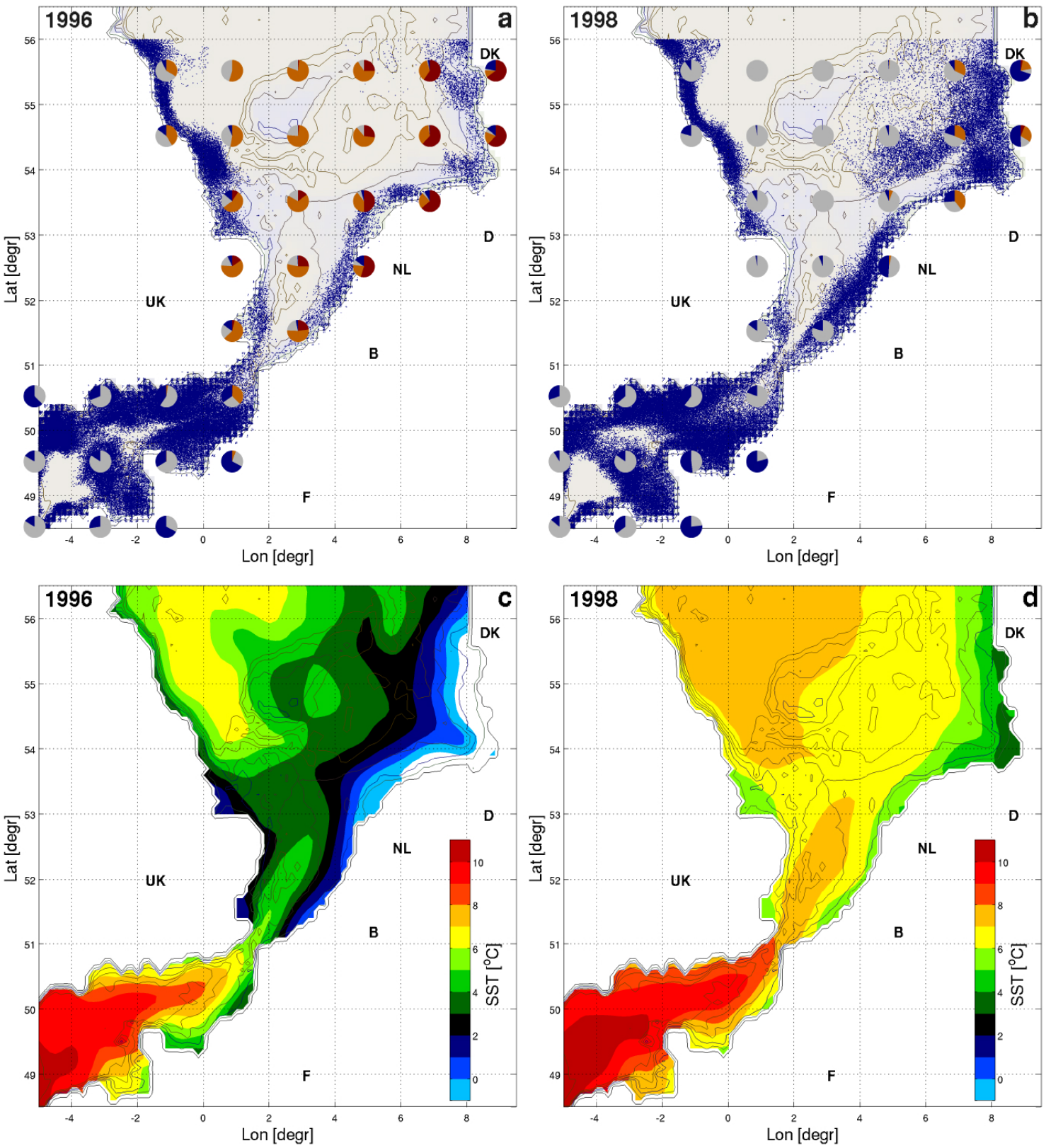

Figure 10. Inter-annual differences (a, c 1996; b, d 1998) in development rates give rise to variations in settlement success (for all 1000000 particles released). (a, b) Particle development characteristics (see Fig. 6 for an explanation of the colour coding); (c, d) sea surface temperature in February.

increased numbers of particles that show truncated development (correlation coefficient of 0.68), as shown in Fig. 12.

Water temperature in the western part of the North Sea (station b) showed less variability over the years (Fig. 14), as the residual current patterns (and therefore also variations in this) generally resulted in temperature effects along the eastern shores. This was also (partially) the reason for the more constant number of particles settling along the UK's North Sea coast. Similarly, the higher temperatures recorded in the English Channel (station d) resulted in all particles reaching the end of their settling stage in this area, therefore also (partially) explaining the reasonably constant settlement numbers in this area over the years. Wind conditions also influenced particle settlement success. In general, years with increased numbers of particles settling along the eastern North Sea shores (specifically 1998, 2000, 2002, 2004 and 2005 see Fig. 13) coincided with strong south-westerly winds in the English Channel (see Table 2, correlation coefficient of 0.79 for the eastern Southern Bight coast, and 0.71 for the western Wadden Sea) and to a limited extent in 
Table 2. Relationship between forcing conditions (at station d) and settlement dynamics at the different coastal zones (see Fig. 13 for a description of the different coastal zones). Bold numbers indicate a high correlation, whereas numbers in italics correspond to low correlation coefficients.

\begin{tabular}{lrrrrr}
\hline & Mean & SD & CV $(\%)$ & Corr. Temp & Corr. Wind \\
\hline UK North Sea & 20647 & 1708 & 8 & -0.13 & -0.12 \\
English Channel & 69145 & 4101 & 6 & -0.63 & $\mathbf{- 0 . 7 1}$ \\
Eastern Southern Bight & 4153 & 931 & 22 & 0.43 & $\mathbf{0 . 7 9}$ \\
Western Wadden Sea & 8264 & 2535 & 31 & 0.37 & $\mathbf{0 . 7 1}$ \\
Northern Wadden Sea & 4646 & 1686 & 36 & 0.18 & 0.52 \\
Denmark and Norway & 12557 & 8995 & 72 & $\mathbf{0 . 7 9}$ & 0.52 \\
\hline
\end{tabular}
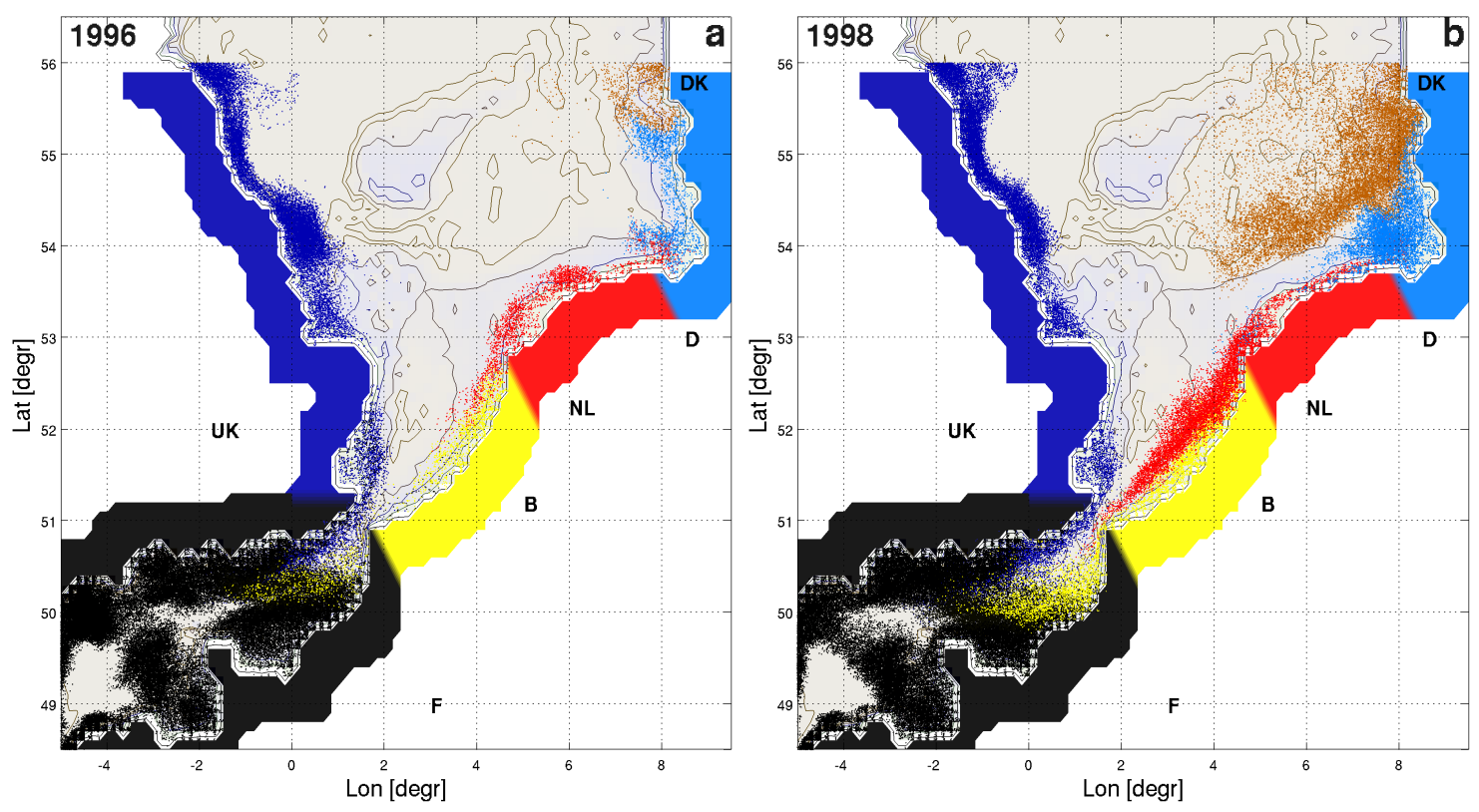

Figure 11. Settle locations of all particles shown in the colour of the dots, for different years (a 1996; b 1998). For explanation of colour coding see Fig. 7.

the Southern Bight (not shown), similar to those observed for 1998 (shown in Fig. 9). However, years with small settlement values for the most northerly settlement areas (shown in orange, in particular 1997, 2001 and 2003) generally coincided with smaller than normal wind speeds in the English Channel (correlation coefficient of 0.52 ).

\subsection{Settlement in the western Wadden Sea}

The western Wadden Sea forms one of the main nursery areas of plaice juveniles in the North Sea basin (Zijlstra, 1972). In the following section, settlement characteristics for this area have been studied in more detail, to highlight not only interannual variability in settlement dynamics, but also present some intra-annual processes that are caused by variability in the hydrodynamic conditions.

The characteristics and origin of particles settling in this domain are presented in Figs. 15 and 16. The settlement area that is considered to represent the western Wadden Sea, geographically roughly encompasses the Marsdiep-Vlie inlet system; although with the low model resolution used in these runs, neither can be distinguished here. To compensate for this low resolution the settlement domain was chosen to partially encompass the neighbouring North Sea as well (black box in Fig. 15a, c, e). Please note that, as was previously the case, the settlement domain is further limited solely to grid cells where the water depth of at least one grid-point is below $10 \mathrm{~m}$.

In Fig. 15 a link between the origin of particles settling in the western Wadden Sea, and the relation between the release and arrival times in this area were investigated for the three years already discussed in Sect. 3.3. The variability in origin of particles settling in the western Wadden Sea was strongly dependent on wind patterns, and showed great inter-annual variability, as was discussed in the previous section. However, also the moment of settlement in this area was strongly variable. In 1996, low water temperatures prolonged particle 


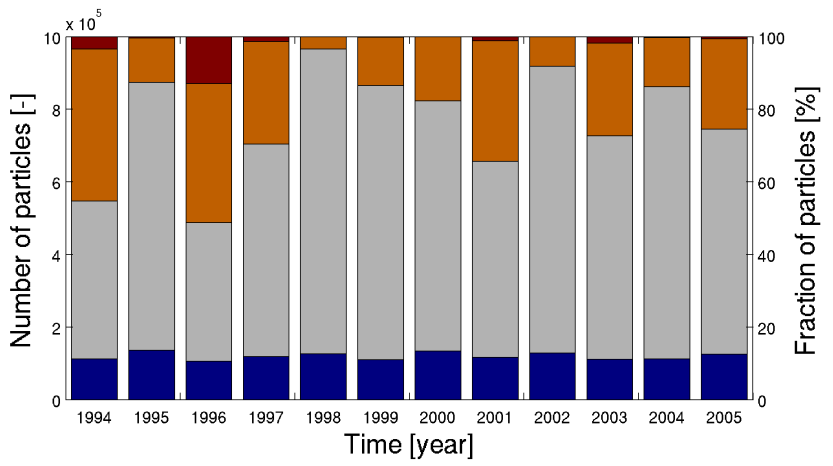

Figure 12. Final status of all particles for each year: (blue) particles that settle; (grey) particles that do not settle; (orange) particles that do not settle but also do not reach end of the 30-day settlement stage before the numerical simulation is truncated after 120 days; (red) particles that do not settle as these have not yet reached the beginning of their 30-day settlement stage, before simulation is truncated.

development, and only after yearday 145 , particles started to settle in the domain. These particles were released around yearday 25 , meaning that the particle drift duration lasted the 120-day simulation limit (an investigation into the consequences of this 120-day simulation limit can be found in Sect. 3.5). This was in stark contrast with 1998 and 2001, when particles that were released during the entire simulation period settle. The distributions of release times versus settling times for 1998 and 2001 (Fig. 15d, f) show a temperature-related, curved lower boundary of the settlement distribution. For 2001, initially a small effect of the 120-day simulation limit can also be observed at the upper-boundary of the distribution; instead of it being similarly curved as the lower boundary, it is straight and following the 120-day limit. During the early stages of the model simulation, water temperatures dropped, causing the particle development to be prolonged, resulting in a shorter duration over which particles could settle. With the gradual increase of water temperatures in spring, development accelerated, and particles could settle earlier. Under extremely cold conditions (as happened in 1996) the temperature related bottom-curve cut through the 120-day limit, inhibiting any particles to settle for the duration of this colder period. The minor differences in forcing conditions experienced for 1998 and 2001 seem to balance each other out with regards to the origin of the settling particles. The stronger south-westerly winds for 1998 caused the particles to propagate faster. However, the coinciding higher water temperatures resulted in a reduction in the drift duration (as can be seen in the slightly earlier settle times of particles in 1998). As a result, the maximum drift distance (the yellow dots) was fairly similar for 1998 and 2001. There was a rough sorting through the settlement time in the origin of particles: in 1998 in particular, particles from the Dover Straight (shown in yellow in Fig. 15) generally arrived during

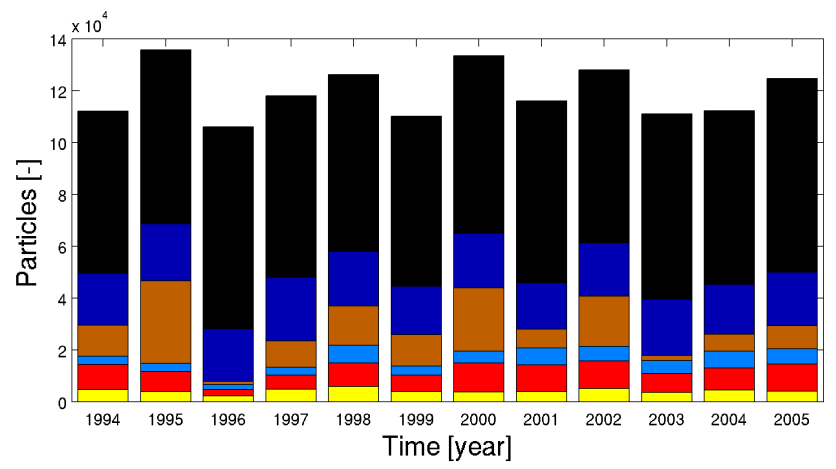

Figure 13. Numbers of particles settling in the different coastal zones for the different years: (dark blue) settlement in the North Sea coastal zone of the UK; (black) settlement in the English Channel; (yellow) settlement along the French, Belgian and Dutch North Sea coast; (red) settlement in the western part of the Wadden Sea; (light blue) settlement in the northern part of the Wadden Sea; (orange) settlement outside of the shown domain (generally along the northern Danish and Norwegian coast).

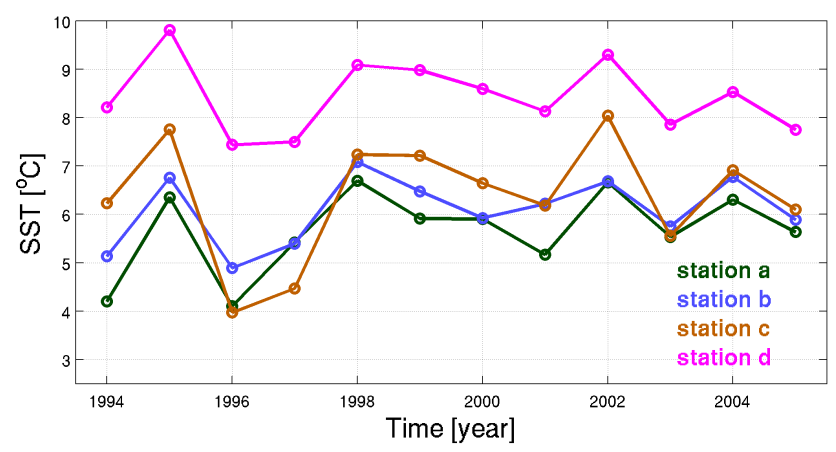

Figure 14. Sea surface temperature for the different years of particle distribution runs, averaged over February for each year. The colour of the lines represents the different stations as presented in Fig. 8.

the start of the year, whereas particles that originated from close to the settlement domain (purple and blue) mainly arrived in the second half of the modelled period. Another remarkable feature was that the particles released close to the settle area (blue) settled after the shortest drift duration (release time-settle time). Also of note was the grouping of settling particles at certain moments in time (right-hand side of Fig. 15). During periods of several days very small numbers of particles settled, whereas at other moments particles released from a broad range of release times all settled at once (for instance just before yearday 160 in 2001, the particles that settled were released from yearday 40 until yearday 90). Only occasionally did the wind conditions force particles into the western Wadden Sea, causing large numbers of particles to drift into suitable settling areas. 

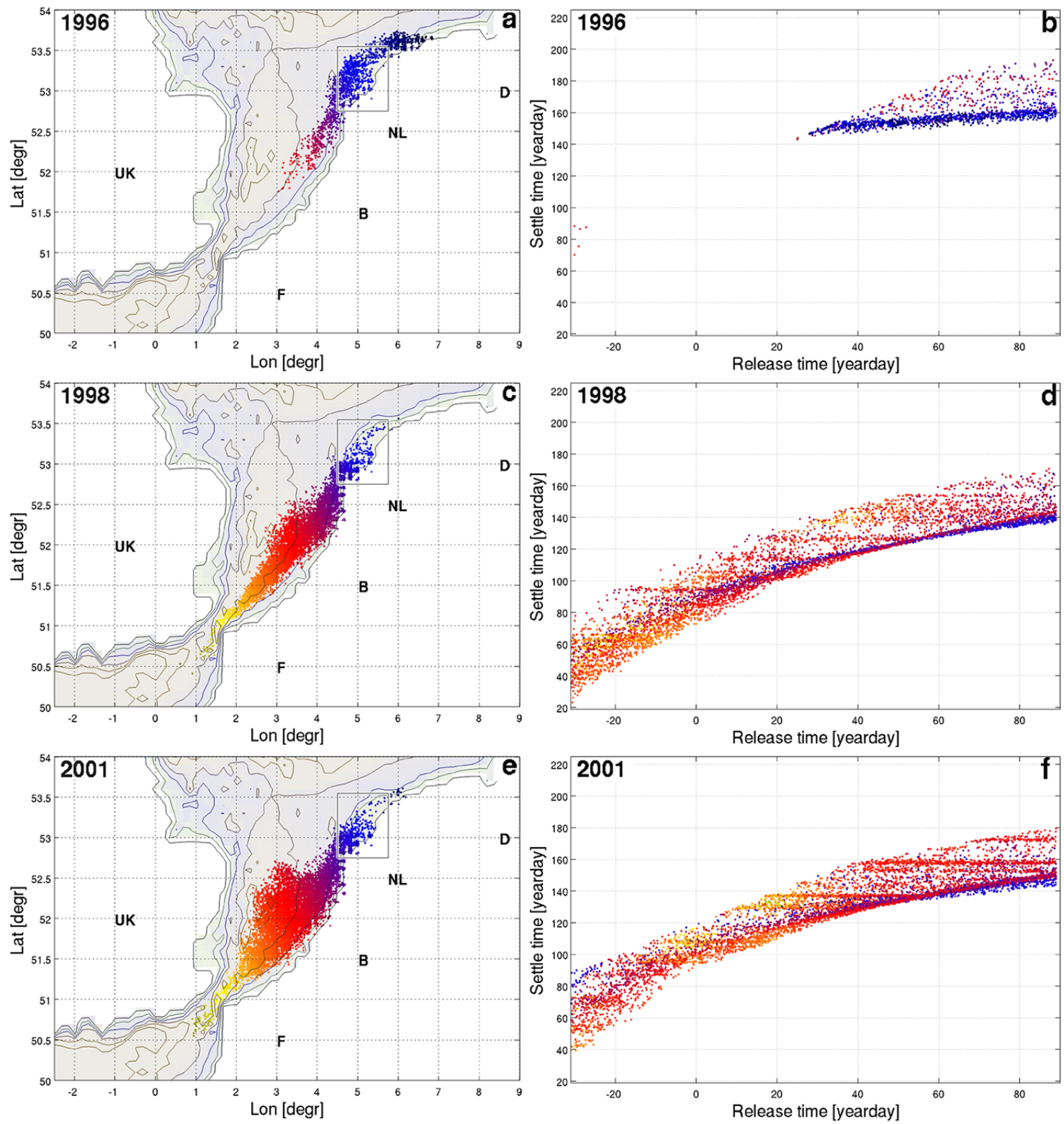

Figure 15. Particle settlement in the western Wadden Sea. (a, c, e) Release position of particles settling in the western Wadden Sea (shown as a black box). The colour of the dots represents the release position of the particles. (b, d, f) The drift duration, presented as the link between the release time and settle time of the particles. Colour coding is the same as in (a, $\mathbf{c}, \mathbf{e})$. The curved bottom edge is the result of the development rate of the particles: colder temperatures in late winter (release time around yearday 30) result in prolonged development rates. The threshold at the top of the plots is primarily the result of the 30-day development threshold. (a, b) 1996; (c, d) 1998 ; (e, f) 2001.

A comparison over all the modelled years of the settle times and drift durations can be seen in Fig. 16 where the maximum drift duration of 120 days is presented as a vertical edge in the distribution, while the diagonal distribution edges at the bottom (clearly visible for instance in 1995 and 1998) and top (visible for all years) correspond with the start and end of the simulated spawning period. Using the same colour coding of the dots as in Fig. 15, the features observed for the 3 years studied above can be recognised for most other years. With regards to the temperature-related threshold in drift duration shift over the years, colder years see a prolonged development duration before settling commences. This shift corresponded well with the surface water temperatures observed in Fig. 14 (especially for stations $\mathrm{c}$ and d). The origin of particles also varied over the years, with particles in 1994 and 1995 (dark yellow) originating furthest away, well into the English Channel. Years with the largest drift distances generally coincided with stronger winds from 


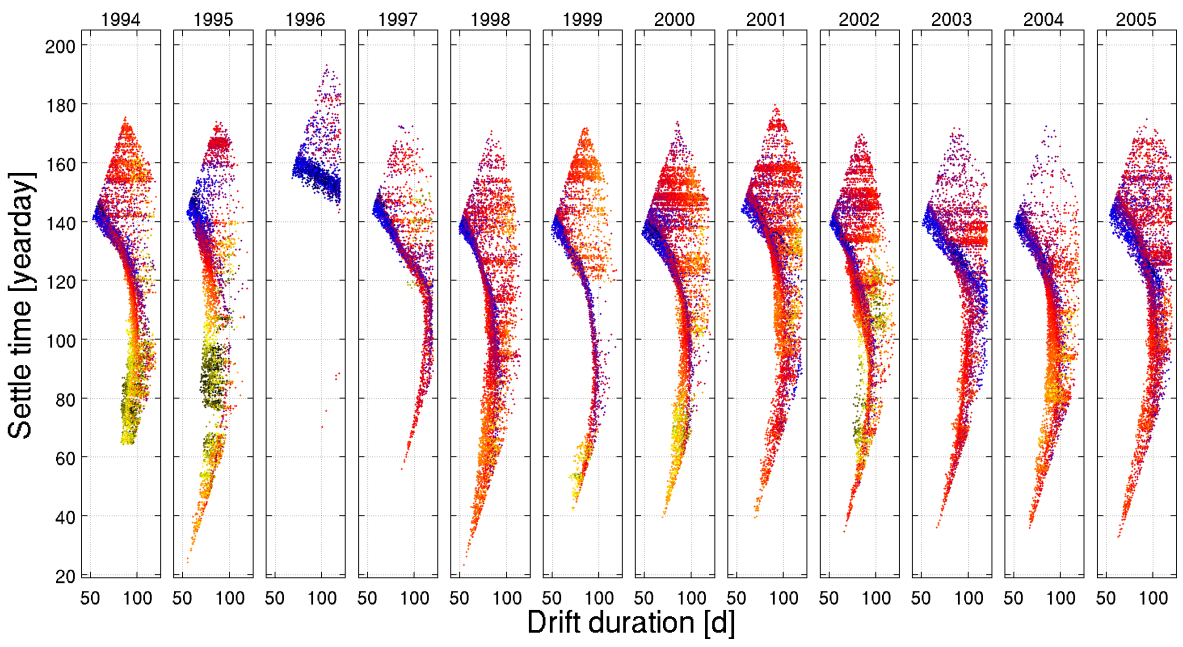

Figure 16. Drift duration and settle time of particle settling in the western Wadden Sea for the period 1994-2005. Colour of the dots represents again the distance from the settle location, and is the same as in Fig. 15.

the SW for the two southerly stations (c and d, with correlation coefficients of 0.70 and 0.66 , respectively). The particles originating from the area closest to the settlement domain (in blue) seemed to settle after the shortest drift duration, but only when water temperatures had increased to enable the particles to reach their settle stage early (which generally occurs around yearday 140). Prior to that, particles released further south, experienced warmer temperatures promoting faster development and earlier settlement. The direct relationship between development rate and sea water temperature, results in high correlation coefficients between the SST for February for stations $\mathrm{c}$ and $\mathrm{d}$ and the average drift duration ( -0.88 and -0.95 respectively).

\subsection{Sensitivity analysis}

In the previous numerical simulations, various settings were used whose impact on the particle success rate is investigated in the following section.

Firstly, a $10 \mathrm{~m}$ depth limit was chosen to define the boundaries of suitable settlement areas (for at least one corner of the grid cell). The effect of changing this threshold on settlement levels not only shows an increase in the total number of settling particles, but also indicates a shift in importance of different settlement areas (Fig. 17). Settlement in the English Channel (black) was relatively constant for different settlement depths. The depth in this region was in general significantly larger than in the other areas. In 1996, the settlement in the Southern and German bights of the North Sea was non-existent, as the particles were released in a very cold period, truncating their development (see Sect. 3.3). Additionally, the settlement along the English coast (dark blue) showed an (relatively) abrupt increase in settling particles, when the settle-depth threshold was increased from 15 to $20 \mathrm{~m}$, which is caused by the Dogger Bank coming into play, and becoming a suitable settlement area. All other areas showed a more constant increase in the number of settling particles, with the increasing settlement depth. The increasing settlement depth forces the boundaries of the settlement areas gradually outwards, enabling particles that drift further offshore to settle.

In this research, the hydrodynamic conditions were updated every $45 \mathrm{~min}$. This value was chosen to give a high enough temporal resolution to describe the M2 tidal cycle. However, in other particle tracking publications, larger hydrodynamic update intervals are generally used (Van der Veer et al., 1998; Hufnagl et al., 2013). The impact of larger hydrodynamical time steps, was evaluated by reproducing the drifter-buoy tracks discussed in Sect. 3.1, whereby the hydrodynamic update interval was varied from $45 \mathrm{~min}$ to $24 \mathrm{~h}$ (Fig. 18), with all the values above $45 \mathrm{~min}$ being averages over the specified periods. In general, tracks that showed large residual currents were reasonably well reproduced for bigger hydrodynamic update intervals (not shown). However, if the residual current was less important, the coarser temporal interval caused significant differences between the different modelled tracks to develop. A low frequency of the hydrodynamic updates could be very computationally advantageous. However, by substituting the tidal motion with tidally averaged motion, even the residual drift patterns could not be well reproduced.

Another aspect studied here is the impact of the temperature-dependent development rate of plaice eggs and larvae on their settlement success. To investigate this, results for a fixed development duration were compared to the temperature-dependent development. In the new set-up, the development duration was set at 80 days (similar to the average duration for settling particles in 2001), after which the particles would have 30 days to settle (the same as in the other simulations). Results presented in Fig. 19, show a change with regards to drift duration, which in the fixed 


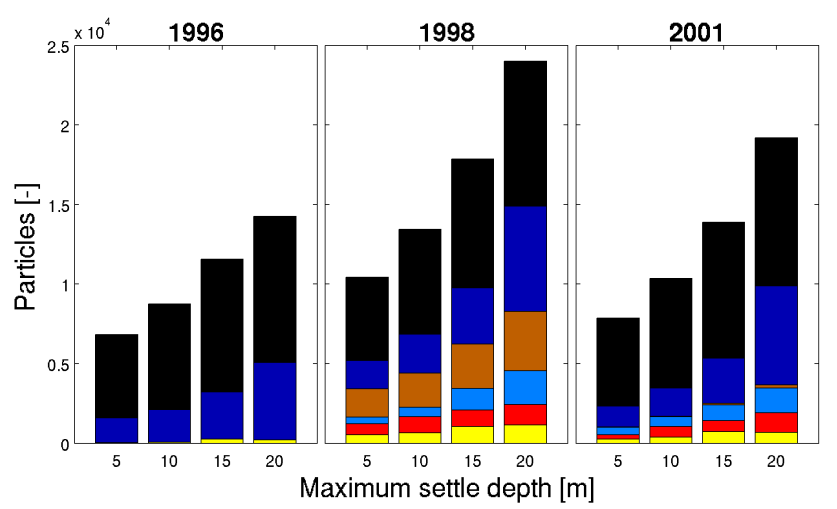

Figure 17. Settlement into the different areas as shown in Fig. 7, for different maximum settle depths for 1996, 1998 and 2001. Only 100000 particles released around 1 January, are taken into consideration (similar to Fig. 5).

development duration case lacks the prolonged development rates during the colder periods. Additionally, the results for 1996 show a larger number of settling particles when this constant development duration is applied. However, the origin of the particles as well as the settlement time (in particular for 1998 and 2001) remain relatively unchanged, and seem to be the result mainly of the current patterns (as can also be seen in Table 2).

The impact of the 120-day simulation limit on the results presented here is considered by comparing the original results with those with a prolonged drift duration. In these new results, the numerical simulation limit was extended to 180 days. Figure 20 shows the release times against settlement times for particles settling in the western Wadden Sea for the 3 years already presented in Fig. 15. The main differences can be observed for 1996, where in the original result a release period existed when no particles would eventually settle. In the new simulations, this gap cannot be observed. The timing of settlement does not change significantly though, as the main settlement time has only shifted around 10 days (from yearday 160 to yearday 150). In the new simulations, settlement commences during a fairly brief period. This indicates that particles show a very wide range of drift durations before settling; for particles released in December, drift durations can last up to 170 days, whereas at the end of the simulations, this has been reduced to around 100 days. A large portion of settling particles that were released in December originated around the German Bight. To what extent these results would be observed in the field remains to be seen, as spawning is expected to occur only in February and March that far east. For 1998 and 2001, the increase in the maximum lifespan does not result in significant changes to the number, origin and distribution of the settling plaice. Furthermore, for all 3 years examined here, the extension of the simulation duration resulted only in a slight broadening in the origin of particles settling in this area, and the overall origin and timing of settlement was also not altered significantly.

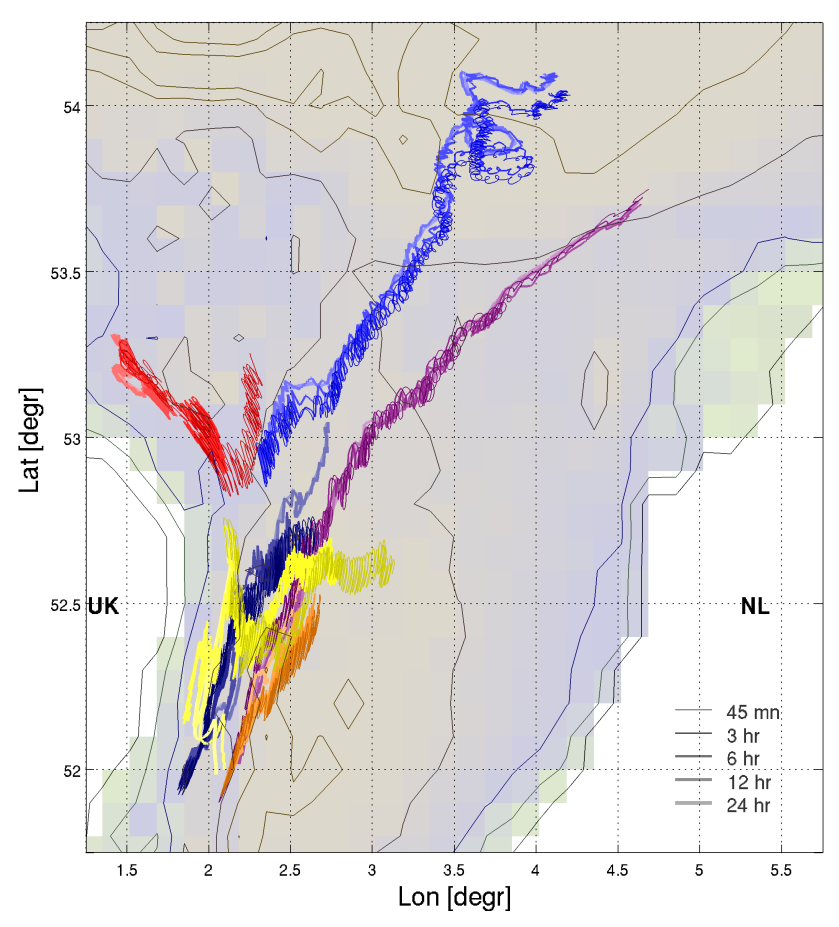

Figure 18. The effect of altering the hydrodynamic forcing time step on the particle drift paths, reproducing the drifting buoys (discussed in Sect. 3.1). In the particle tracking routine, the hydrodynamics were updated every $45 \mathrm{~min}$, every 3612 and $24 \mathrm{~h}$. These update intervals are shown in the thickness and darkness of the lines, while the colour of the lines correspond to the different drifter buoys (as presented in Fig. 3).

\section{Discussion}

The aim of this research was to investigate whether changes in hydrodynamic conditions alone can potentially cause significant inter-annual settlement variability of North Sea plaice juveniles whereby the focus was to investigate the influence of hydrodynamic forcing on plaice egg and larval drift patterns and not to reproduce the actual settlement demographics. In the following sections, various aspects concerning the findings presented here are put into a broader perspective. Both a comparison with other simulations, as well as several steps towards a future comparison with observations of settlement data are discussed.

\subsection{Overall findings}

The simulations of plaice drift and settlement showed that the inter-annual changes to the environmental conditions (specifically water temperature and wind forcing) significantly influence drift direction and distance, as well as settlement dynamics along the eastern shores of the North Sea (CV $37 \%$ ). Strong south-westerly wind speeds in the English Channel and Southern Bight generally coincided with higher drift distances for particles settling in the western Wadden Sea 


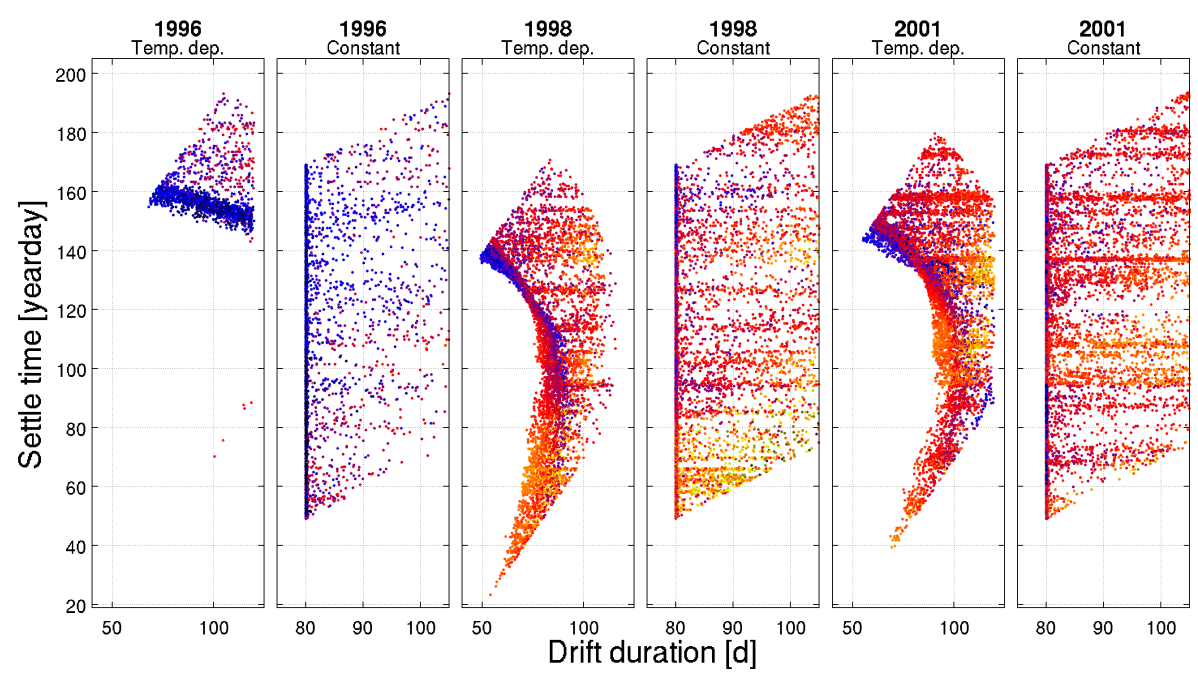

Figure 19. Comparison between the temperature-dependent development rate and a fixed development duration for 1996,1998 and 2001. Shown is the drift duration against the settlement time for particles settling in the western Wadden Sea.

(correlation coefficient of 0.66 and 0.70 respectively). Effectively, these winds enhance the general anticlockwise circulation pattern that transports particles from the Southern Bight and English Channel along the eastern shores of the North Sea and past various nursery areas. Years with reduced (or reversed) wind direction and intensity (for instance 1996) result in significant changes to this general observed drift direction. This in turn affects settlement dynamics and changes the connectivity between spawning grounds and nursery areas. In 1996 the origin of settling plaice juveniles in the western Wadden Sea was significantly shifted towards the east, in comparison to most other years (see Fig. 16). Strong winds result in a large influx of warmer English Channel water into the Southern Bight, increasing water temperature, and reducing drift durations for particles settling in the western Wadden Sea (correlation coefficient of -0.88 ). As mortality has not been included in the present set-up, the impact of prolonged drift durations on survivability has not been studied. Results from field studies of settled plaice juveniles suggest that the accompanying lower temperatures would result in reduced mortality rates (Van der Veer et al., 2000; Van der Veer and Witte, 1999; Bolle et al., 2009). In the present research, years with reduced development rates generally coincide with reduced south-westerly winds and as a result fewer particles settling in the Wadden Sea nursery area.

The results presented here with respect to the drift of particles across the southern North Sea compare well with other papers regarding the general trend and inter-annual variability. The reproduction of the paths of the CEFAS drifter buoys showed that the coupled (GETM-GITM) model reproduced the hydrodynamic conditions reasonably well, with the error between the buoy and the particle for each drifter buoy being less than $10 \%$ of the total drifted distance. Additionally, other studies have shown similar inter-annual variability in the drift paths of fish eggs and larvae: Hufnagl et al. (2013) using an approach similar to the one used here, showed that the connectivity of the different spawning areas to various coastal zones corresponds well with the general settlement dynamics observed here. The same authors indicated similar geographic distributions of development times, partially caused by the same temperature-dependent development rate. With regards to vertical migration of larvae, Savina et al. (2010) showed that for 2 examined years (1995 and 1996) the impact of inter-annual variability in the hydrodynamic conditions on the drift of sole exceeded the influence of various vertical migration regimes. Rochette et al. (2012) showed that for sole the settlement success in the English Channel area shows significant inter-annual variability. This is in contrast to the limited variability in settlement figures for the English Channel presented here. This difference might be due to the different set-up of spawning areas with regards to release area, numbers and timing. One aspect that differed from ours was that spawning figures were based on the number of adults, which varied over the years. However, they concluded that these variable initial conditions only have limited influence on the eventual settlement success. The inter-annual drift patterns of herring were investigated by Dickey-Collas et al. (2009). With slight variations in hatching (release) time around 1 January, similar drift patterns and inter-annual changes were presented as shown here, with the drift during 1996 being significantly shorter than in the majority of the examined years. Bolle et al. (2009) using a two-layer model, showed drift trends during the early life stages (without vertical migration) as those observed here, and corresponding inter-annual variability for Southern Bight spawning grounds. The inter-annual variability in the settlement success of sole is of a similar magnitude relative to the overall settlement as that observed here 

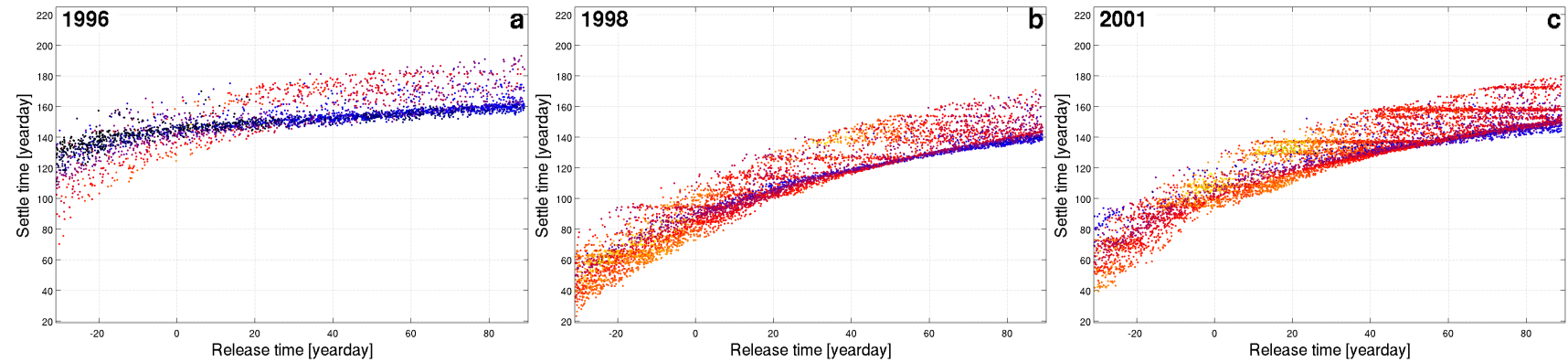

Figure 20. Settlement of particles in the western Wadden Sea, for prolonged numerical simulations (180 days). (a) 1996; (b) 1998; (c) 2001.

in the nursery areas along the eastern shores (Lacroix et al., 2013). Whilst our study showed a significant reduction in settlement in the western Wadden Sea during 1996, the work of Lacroix et al. (2013) suggests that settlement is enhanced for 1996 in comparison to 1998 and 2001. However, the timing of spawning and early life-stage mortality of sole are both temperature-related and, therefore, variable over the years. Additionally, plaice and sole have different spawning seasons and vertical migration is included in the work presented by Lacroix et al. (2013). As a result, the observed drift trends presented here are only partially matched with the results presented by Lacroix et al. (2013): The significant differences between drift distances for 1996, 1998, and to a lesser extent 2001, presented here, correspond to a limited extent to the results presented by Lacroix et al. (2013), where reduced drift distances were observed for 1996 while slightly enhanced drift distances occurred for 1998 and 2001 for sole spawning in the English Channel.

\subsection{Comparison with field data}

No direct comparison between plaice larvae drift patterns and numerical model results is presented here. In fact, such a comparison will face a number of hurdles, placing it beyond the scope of this paper. Comprehensive data sets combining the numbers of plaice eggs at spawning locations, the drift of eggs and larvae along the various transport paths, and of juveniles upon arrival at nursery areas are non-existent. Quantitative field data from spawning grounds is sparse (Taylor et al., 2007), while the drift patterns of plaice are even less well known (Talbot, 1977). Field data that can be obtained most easily is that of the arrival of plaice juveniles in the nursery areas (Van der Veer et al., 2009). Given the uncertainty about plaice spawning areas, numbers and times, and only very sparse data from the egg and larval drift, the numerical simulations can only be linked with settlement data (as was done by for instance Bolle et al., 2009). However, if structured cruise data of egg and larval abundance are available, presence-absence maps can be compiled and compared (Van der Molen et al., 2007). However, assumptions have then to be made about spawning and drift of plaice eggs and larvae.

\subsection{Selection of spawning grounds and periods}

In the present study, particles were released across the entire southern and central North Sea, and also encompassing the English Channel (similar to Hufnagl et al., 2013). Studies of egg abundance in the different parts of the study domain have shown a strong variability in egg abundance over the different areas, as well as over the years (Taylor et al., 2007; Loots et al., 2010a, b). There is some sorting in spawning areas within a year; in the English Channel spawning can already occur in December, whereas the maximum spawning in the German Bight occurs around February and lasts into March (Bergman et al., 1988). In the present set-up, limits could be placed with respect to specific spawning grounds and periods (cf. De Graaf et al., 2004; Bolle et al., 2009). However, the variability over the years as well as the uncertainty in the location and boundaries, start time, and the duration of the different spawning areas in the different parts of the North Sea mean that any limits on these cannot be prescribed based solely on hydrodynamic circumstances, which would inhibit the original aim of this research.

\subsection{Vertical position of plaice eggs and larvae}

To investigate the pre-juvenile drift of fish eggs and larvae, a particle tracking routine may be used that combines hydrodynamic forcing conditions and active behaviour, such as vertical migration, to describe the drift of particles from spawning grounds to nursery areas. With respect to plaice larvae, several studies have been carried out where, during the latter stages of pre-juvenile evolution, it is assumed that plaice show a tendency to migrate vertically over the water column, either in a daily frequency (Rijnsdorp et al., 1985), or over a tidal cycle (de Graaf et al., 2004; Fox et al., 2006, 2009; Van der Molen et al., 2007; Bolle et al., 2009; Hufnagl et al., 2013). The latter will cause plaice larvae to be able to drift faster when the tidal current is towards suitable nursery areas and reduce the backward drift, when the tidal flow is opposite. The overall impact of vertical migration on the particle drift might be limited as it only occurs during the brief later stages of particle development (Bolle et al., 2009). However, the impact on the numbers of juveniles successfully settling 
in a certain domain can be significant, as particles that would otherwise drift too far offshore of the settling area, will now be able to drift towards it (de Graaf et al., 2004; Fox et al., 2006). The presented results show a very strong short-term variability in the numbers of particles arriving in a nursery area. These intra-annual changes in settling figures are forced by local changes in (residual) current patterns. Residual current patterns are however significantly smaller than the tidal currents, and active vertical migration would most likely result in a reduction of these intra-annual fluctuations and cause a more constant flow of particles to settle in the settling domain. Additionally, plaice eggs are assumed to exhibit a positive buoyancy (Coombs et al., 1990), suggesting a higher abundance of plaice eggs in the upper layers of the sea. This has not been incorporated into the present study, but would affect the drift distance during this early development stage since currents are generally enhanced further up the water column.

\subsection{Mortality based on predation and food abundance}

In the present simulations, particles released from very different parts of the North Sea and English Channel drifted into suitable settlement areas. Without food abundance or predation included in the present runs, particle drift is only truncated when a particle settles, or because a particle reaches the end of its pelagic life span, either coming to the end of the 30-day settlement period without settling, or because of reaching the 120-day simulation limit (cf. de Graaf et al., 2004; Van der Molen et al., 2007; Bolle et al., 2009; Hufnagl et al., 2013). As a result (along with the lack of spawningground and -period selection), most years show continuous settlement of particles for almost the entire modelled duration. A constant mortality (Van der Veer et al., 1998) or mortality based on temperature (Fox et al., 2006, 2009) could give insights into the survival rates during egg and larval stages. However, an intra-annual variability in food abundance could form an extra threshold for particle development, and survival. Expressing the changing particle development rate with regards to the particle's dynamic energy budget (DEB) would form a promising way to model more realistic circumstances in which plaice eggs and larvae might evolve. Additionally, intra-annual population dynamics of predator species might give a second input towards seasonal changes in survivability rates of plaice eggs and larvae before settlement.

\subsection{Drift duration}

As was mentioned previously, no direct comparison between numerical simulations and field measurements of numbers of arriving plaice juveniles in the western Wadden Sea is presented, as this would involve unverifiable assumptions towards spawning grounds and periods. However, the total lack of arriving plaice juveniles in the early stages of 1996 in the numerical simulations (Fig. 15) is in stark contrast with the peak in plaice juveniles arriving in the western Wadden Sea according to field studies. However this can also partially be due to lower mortality rates in cold years (Van der Veer et al., 2000; Van der Veer and Witte, 1999; Bolle et al., 2009). In 1996, the development of many particles is truncated due to low water temperatures resulting in slow particle development. The resulting lack of settlement in the western Wadden Sea is caused by slow development rates in combination with the 120-day numerical simulation limit. This limit was chosen based on drift durations presented in previous studies (Bolle et al., 2009; Hufnagl et al., 2013). However the results presented in the sensitivity analysis, concerning the prolonged simulation limit, suggested that both the peak in settlement and the origin of the settling particles only show limited variability.

The duration of the settlement period (30 days), in which particles drift until reaching a suitable settlement area, is based on existing literature (Bolle et al., 2009). The duration of this period influences the settlement dynamics, as a longer (or shorter) period would enable more (or fewer) particles to drift into a suitable settlement area. However, we would like to argue that since the majority of settling particles do so at the onset of the settling period, a reduction in the duration will have smaller impact than the magnitude of the reduction itself would imply.

\subsection{Suitability of settlement areas}

As already discussed in the sensitivity analysis, settlement areas are probably defined by food abundance (cf. Creutzberg et al., 1978) and lack of predation of plaice juveniles, whereas the boundaries of settlement areas are presently solely defined by a threshold water depth. Similar to the possibility to make a priori a selection of spawning grounds and periods, also different nursery areas could be pre-defined based on field data. This would not only lead to an increase in settling particles in the (more limited) number of nursery areas, but also possibly to shifts in importance of different settlement areas. In this respect the Dogger Bank is a puzzling area: settlement does not seem to be successful, however transplantation experiments indicate that it could be a potential nursery area with good growth conditions for plaice (Borley, 1919).

Nursery grounds could be defined based around soil characteristics as well as water depth (similar to Lacroix et al., 2013). These areas could be limited to certain soil compositions, such as fine sands and mud for instance, thereby confining plaice juvenile areas to estuarine environments such as the Wadden Sea. The current assumption that a particle would settle at the first possible opportunity (during their juvenile stage) when a depth of less than $10 \mathrm{~m}$ is encountered is an oversimplification of this process. With better understanding of the ideal settlement conditions and better knowledge of the occurrence of such conditions, a different approach might 
be chosen whereby the drift of particles could be prolonged beyond this first settlement opportunity: if, for instance, environmental conditions would improve with longer drift distances, settlement could then be postponed. In this case, settlement along the Dutch North Sea coast would be avoided, as these particles would tend to propagate further towards the better conditions in the Wadden Sea. Additionally, prolonged drift during this settlement stage may result in juveniles reaching optimal sites within nursery areas with regards to food abundance and predation.

\section{Conclusions}

In this study, we demonstrate a substantial effect of physical factors alone on the inter-annual variability in the transport of eggs and larvae and their subsequent success rate in settling. These idealised studies are not intended to explain or reproduce observations (insofar as they exist, mainly from nursery grounds). This would require that assumptions of spawning grounds and periods, mortality and possibly active behaviour (such as vertical migration) be included in the model. The present study serves therefore to give an indication of the extent of variability that can be attributed to physical factors.

Inter-annual variability in wind speed and direction caused residual current patterns to show significant changes over the years, strongly influencing the direction and distance of the particle drift. As a result, different years had a significant variability in the origin of the particles settling in the different nursery areas. In general, an anticlockwise circulation in the central and southern North Sea could be observed, and a north-easterly drift direction when released in the English Channel. However, in years with strong easterly winds there was less drift along coastlines, and more into the central North Sea, limiting settlement chances and also giving rise to different connections between spawning areas and nursery grounds.

In combination with wind-driven current variability, the sea water temperature also varied over the years. Assuming that particle development was dependent on water temperature, differences in experienced water temperature significantly affected their success rate. With higher temperatures in early winter, late spring and summer, particle development was accelerated, and the settlement stage was reached earlier, thereby reducing the distance between spawning ground and settlement area. A maximum particle lifespan of 120 days in combination with temperature dependent trajectory, meant that for some years (1996 in particular) large numbers of particles did not reach the settling stage before the end of their pelagic lifespan.

Settlement in the western Wadden Sea showed strong inter-annual variability due to changes in the hydrodynamic conditions. Not only did the origin of particles settling in this area vary, but the general arrival time was also influenced by hydrodynamic conditions. Over each season, the origin and drift duration of particles settling in this nursery area changed: during winter, particles generally originated from more distant areas than particles settling in the western Wadden Sea in spring and summer. The low sea water temperatures during late winter and early spring resulted in slower development rates and longer drift durations. Additionally, stronger wind conditions during winter and early spring, generally forced particles to drift further. Settlement success also varied substantially as a result of temporary local conditions: for example, if the right wind conditions prevailed large numbers of particles, whose origin could be widely variable over space and time, would be forced into this settlement area over a short period.

Acknowledgements. The authors would like thank the GETM developers for the use of the numerical code and the two referees for their detailed and useful comments. The authors gratefully acknowledge the ECMWF (European Centre for Medium Range Weather Forecasting) for allowing use of the meteorological data. The authors thank all contributors to the daily riverine loads database. French water quality data were supplied by the Agence de l'eau Loire-Bretagne, Agence de l'eau Seine-Normandie and IFREMER. UK water quality data were processed from raw data provided by the Environment Agency, the Scottish Environment Protection Agency and the National River Flow Archive. The German river loads are based on data from the ARGE Elbe, the Niedersächsisches Landesamt für Ökologie and the Bundesanstalt für Gewässerkunde. The river load data for the Netherlands were supplied by the DONAR database. Drifter observations supplied by DEFRA project AE1225.

Edited by: E. J. M. Delhez

\section{References}

Aldridge, J., van der Molen, J., and Forster, R.: Wider ecological implications of Macroalgae cultivation, ISBN: 978-1-906410-38-4, 95 pp., The Crown Estate, Lowestoft, UK 2012.

Bergman, M. J. N., Veer, H. W., and Zulstra, J. J.: Plaice nurseries: effects on recruitment, J. Fish Biol., 33, 201-218, 1988.

Boero, F., Bouillon, J., and Gravili, C.: The life cycle of Hydrichthys mirus (Cnidaria: Hydrozoa: Anthomedusae: Pandeidae), Zool. J. Linn. Soc., 101, 189-199, 1991.

Bolle, L. J., Dickey-Collas, M., van Beek, J. K. L., Erftemeijer, P. L. A., Witte, J. I. J., van der Veer, H. W., and Rijnsdorp, A.: Variability in transport of fish eggs and larvae. III. Effects of hydrodynamics and larval behaviour on recruitment in plaice, Mar. Ecol. Prog. Ser., 390, 195-211, 2009.

Borley, J. O.: Report on the Experimental Transplantation of Plaice to the Dogger Bank Carried Out by the Marine Biological Association in the Years 1904-8, 79 pp. Lowestoft Laboratories, Lowestoft, UK, 1919.

Burchard, H. and Bolding, K.: GETM - A general estuarine transport model, Scientific documentation (Technical report No. EUR 20253 EN), European Commission, 2002.

Coombs, S. H., Nichols, J. H., and Fosh, C. A.: Plaice eggs (Pleuronectes platessa L.) in the southern North Sea: abundance, 
spawning area, vertical distribution, and buoyancy, J. du Cons., 47, 133-139, 1990.

Creutzberg, F., Eltink, A. T. G. W., and van Noort, G. J.: The migration of plaice larvae Pleuronectes platessa into the western Wadden Sea, in: Proc. 12th Europ. Mar. Biol. Symp. Presented at the Physiology and behaviour of marine organisms, edited by: McLusky, D. S. and Berry, A. J., Pergamon Press, New York, 243-251, 1978.

Dale, B.: Dinoflagellate cysr analysis of upper quaternary sediments in core GIK-15530-4 from the Skagerrak, Nor. Geol. Tidsskr., 65, 97-102, 1985.

De Graaf, M., Jager, Z., Vreugdenhil, C. B., and Elorche, M.: Numerical simulations of tidally cued vertical migrations of flatfish larvae in the North Sea, Estuar. Coast. Shelf S., 59, 295-305, 2004.

Dickey-Collas, M., Bolle, L. J., van Beek, J. K. L., and Erftemeijer, P. L. A.: Variability in transport of fish eggs and larvae. II. Effects of hydrodynamics on the transport of Downs herring larvae, Mar. Ecol. Prog. Ser., 390, 183-194, 2009.

Fox, C. J., Mccloghrie, P., Young, E. F., and Nash, R. D. M.: The importance of individual behaviour for successful settlement of juvenile plaice (Pleuronectes platessa L.): a modelling and field study in the eastern Irish Sea, Fish. Ocean., 15, 301-313, 2006.

Fox, C. J., McCloghrie, P., and Nash, R. D. M.: Potential transport of plaice eggs and larvae between two apparently self-contained populations in the Irish Sea, Estuar. Coast. Shelf S., 81, 381-389, 2009.

Gräwe, U. and Burchard, H.: Storm surges in the Western Baltic Sea: the present and a possible future, Clim. Dynam., 39, 165183,2011

Harding, D., Nichols, J. H., and Tungate, D. S.: The spawning of plaice (Pleuronectes platessa) in the southern North Sea and English Channel, Rapp. Procès Verbaux Réunions Cons. Int. Pour Explor. Mer, 172, 102-113, 1978.

Hufnagl, M., Peck, M. A., Nash, R. D. M., Pohlmann, T., and Rijnsdorp, A. D.: Changes in potential North Sea spawning grounds of plaice (Pleuronectes platessa L.) based on early life stage connectivity to nursery habitats, J. Sea Res., 84, 26-39, 2013.

Hunter, J. R., Craig, P. D., and Philips, H. E.: On the use of random walk models with spatially variable diffusivity, J. Comput. Phys., 106, 366-376, 1993.

Janssen, F., Schrum, C., and Backhaus, J. O.: A climatological data set of temperature and salinity for the Baltic Sea and the North Sea, Dtsch. Hydrogr. Z., 51, 5-245, 1999.

Lacroix, G., Maes, G. E., Bolle, L. J., and Volckaert, F. A. M.: Modelling dispersal dynamics of the early life stages of a marine flatfish (Solea solea L.), J. Sea Res., 84, 13-25, 2013.

Leggett, W. C. and Deblois, E.: Recruitment in marine fishes: Is it regulated by starvation and predation in the egg and larval stages?, Neth. J. Sea Res., 32, 119-134, 1994.

Lenhart, H.-J., Mills, D. K., Baretta-Bekker, H., van Leeuwen, S. M., van der Molen, J., Baretta, J. W., Blaas, M., Desmit, X., Kühn, W., Lacroix, G., Los, H. J., Ménesguen, A., Neves, R., Proctor, R., Ruardij, P., Skogen, M. D., Vanhoutte-Brunier, A., Villars, M. T., and Wakelin, S. L.: Predicting the consequences of nutrient reduction on the eutrophication status of the North Sea, J. Mar. Syst., 81, 148-170, 2010.
Loots, C., Vaz, S., Koubbi, P., Planque, B., Coppin, F., and Verin, Y.: Inter-annual variability of North Sea plaice spawning habitat, J. Sea Res., 64, 427-435, 2010a.

Loots, C., Vaz, S., Koubbi, P., Planque, B., and Koubbi, P.: Spawning distribution of North Sea plaice and whiting from 1980 to 2007, J. Oceanogr., Research and Data, 3, 77-95, 2010 b.

Niiler, P. P., Sybrandy, A. S., Bi, K., Poulain, P. M., and Bitterman, D.: Measurements of the water following capacity of holeysock and tristar drifters, Deep Sea Res., 42, 1951-1964, 1995.

Otto, L., Zimmerman, J. T. F., Furnes, G. K., Mork, M., Saetre, R., and Becker, G.: Review of the physical oceanography of the North Sea, Neth. J. Sea Res., 26, 161-238, 1990.

Rijnsdorp, A. D., van Stralen, M., and van der Veer, H. W.: Selective Tidal Transport of North Sea Plaice Larvae Pleuronectes platessa in Coastal Nursery Areas, T. Am. Fish. Soc., 114, 461-470, 1985.

Rochette, S., Huret, M., Rivot, E., and Le Pape, O.: Coupling hydrodynamic and individual-based models to simulate long-term larval supply to coastal nursery areas, Fish. Oceanogr., 21, 229242, doi:10.1111/j.1365-2419.2012.00621.x, 2012.

Ruardij, P., Veldhuis, M. J. W., and Brussaard, C. P. D.: Modeling the bloom dynamics of the polymorphic phytoplankter Phaeocystis globosa: impact of grazers and viruses, Harmful Algae, 4, 941-963, 2005.

Savina, M., Lacroix, G., and Ruddick, K.: Modelling the transport of common sole larvae in the southern North Sea: Influence of hydrodynamics and larval vertical movements, J. Mar. Syst., 81, 86-98, 2010.

Sinclair, M.: Marine populations: an essay on population regulation and speciation, Books in recruitment fishery oceanography, Washington Sea Grant Program?: Distributed by University of Washington Press, Seattle [Wash.], 1988.

Sündermann, J. and Pohlmann, T.: A brief analysis of North Sea physics, Oceanologia, 53, 663-689, 2011.

Talbot, J. W.: The dispersal of plaice eggs and larvae in the Southern Bight of the North Sea, J. Cons., 37, 221-248, 1977.

Taylor, N., Fox, C. J., Bolle, L., Dickey-Collas, M., Fossum, P., Kraus, G., Munk, P., Rolf, N., van Damme, C., Vorbach, M., Taylor, N., Fox, C. J., Bolle, L., Dickey-Collas, M., Fossum, P., Kraus, G., Munk, P., Rolf, N., van Damme, C., and Vorbach, M.: Results of the Spring 2004 North Sea Ichthyoplankton Surveys. The distribution of fish eggs and larvae from the International Ichthyoplankton Survey, 2007.

Thorson, G.: Some factors influencing the recruitment and establishment of marine benthic communities, Neth. J. Sea Res., 3, 267-293, 1966.

Van der Molen, J., Rogers, S. I., Ellis, J. R., Fox, C. J., and McCloghrie, P.: Dispersal patterns of the eggs and larvae of springspawning fish in the Irish Sea, UK, J. Sea Res., 58, 313-330, 2007.

Van der Veer, H. W.: Immigration, settlement and dependent mortality of a larval and early post-larval 0-group plaice (Pleuronectes platessa) population in the western Dutch Wadden Sea, Mar. Ecol. Prog. Ser., 29, 223-236, 1986.

Van der Veer, H. W. and Leggett, W. C.: Recruitment, in: Flatfishes, edited by: Gibson, R. N., Blackwell Science Ltd, Oxford, UK, 120-137, 2005.

Van der Veer, H. W. and Witte, J. I. J.: Year-class strength of plaice Pleuronectes platessa in the Southern Bight of the North Sea:a 
validation and analysis of the inverse relationship with winter seawater temperature, Mar. Ecol. Prog. Ser., 184, 245-257, 1999.

Van der Veer, H. W., Ruardij, P., Van den Berg, A. J., and Ridderinkhof, H.: Impact of interannual variability in hydrodynamic circulation on egg and larval transport of plaice Pleuronectes platessa L. in the southern North Sea, J. Sea Res., 39, 29-40, 1998.

Van der Veer, H. W., Geffen, A. J., and Witte, J. I. J.: Exceptionally strong year classes in plaice Pleuronectes platessa:are they generated during the pelagic stage only, or also in the juvenile stage?, Mar. Ecol. Prog. Ser., 199, 255-262, 2000.

Van der Veer, H. W., Bolle, L. J., Geffen, A. J., and Witte, J. I. J.: Variability in transport of fish eggs and larvae. IV. Interannual variability in larval stage duration of immigrating plaice in the Dutch Wadden Sea, Mar. Ecol. Prog. Ser., 390, 213-223, 2009.
Van Leeuwen, S. M., van der Molen, J., Ruardij, P., Fernand, L., and Jickells, T.: Modelling the contribution of deep chlorophyll maxima to annual primary production in the North Sea, Biogeochemistry, 113, 137-152, 2012.

Wolk, F.: Three-dimensional Lagrangian Tracer Modelling in Wadden Sea Areas (Diploma thesis), Carl von Ossietzky University, Oldenburg, 2003.

Zijlstra, J. J.: On the importance of the Waddensea as a nursery area in relation to the conservation of the southern North Sea fishery resources, Symp. Zool. Soc. Lond., 19, 233-258, 1972. 